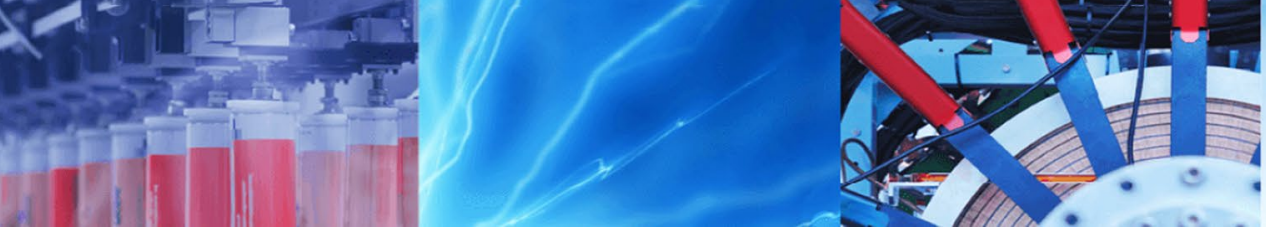

Research Article

\title{
How will treatment parameters impact the optimization of hydraulic fracturing process in unconventional reservoirs?
}

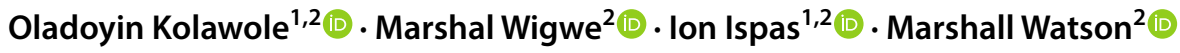

Received: 15 April 2020 / Accepted: 14 October 2020 / Published online: 23 October 2020

(c) Springer Nature Switzerland AG 2020

\begin{abstract}
Hydraulic fracturing is a very complex process that has not yet been fully understood. Furthermore, the number of stages, length of fracture clusters in each stage, proppant and fracturing fluid compatibilities, optimum spacing length, proppant transport and placement, proppant and frac-fluid compatibility, and optimum spacing are some of the challenges inhibiting successful application of this technique across the world. In this study, we present the impact of fracture-cluster lengths, proppant types and sizes, proppant densities, frac fluid types, fluid viscosities, and injection rates on hydraulic fracturing process. Firstly, we developed a stress profile to determine initiation location and orientation of the hydraulic fractures, and subsequently created the geological layering in the zone of interest. We grouped our investigations into 5 case studies, followed by developing an efficient hydraulic fracturing design approach, and we determined the optimal treatment to achieve maximum recovery. Our results show that fracture clusters with optimal lengths will provide optimized hydraulic fracture treatment. In addition, high-strength proppants is efficient for shale formations with closure stress exceeding 5000 psi to achieve optimum fracture conductivity and fracture half-length. Furthermore, we observed the high-density proppant produced greater fracture lengths and lower dimensionless fracture conductivity $\left(\mathrm{C}_{\mathrm{FD}}\right)$, while the low-density proppant produced greater effective propped-fracture lengths and higher $\mathrm{C}_{\mathrm{FD}}$. In some of the cases investigated, we observed that stress shadowing and interference can hinder fracture growth, eventually led to a collapse of some fractures. Our results provide valuable critical decision-making insight for optimizing hydraulic fracturing process in unconventional reservoirs across the world.
\end{abstract}

Keywords Hydraulic fracturing · Tight reservoir · Fracturing treatment · Shale · Eagle ford · Unconventional reservoir

\begin{tabular}{|c|c|c|c|}
\hline \multicolumn{2}{|l|}{ AD } & $k$ & Elliptical integral parameter \\
\hline$\sigma$ & Minimum horizontal stress (MPa) & Vps & Uncorrected proppant settling velocity \\
\hline$p$ & $\begin{array}{l}\text { Fluid pressure inside the propagating fracture } \\
\text { (MPa) }\end{array}$ & $\begin{array}{l}\rho_{p^{\prime}} \rho_{f} \\
d p\end{array}$ & $\begin{array}{l}\text { Proppant and fracturing fluid density } \\
\text { Proppant diameter }\end{array}$ \\
\hline$E$ & Young's modulus of the formation rock & $V p s^{\prime}$ & Corrected proppant settling velocity \\
\hline & s ratio of the for & Vps & d proppant settling velocity \\
\hline & fracture surface energy $\left(10^{4} \mathrm{erg} / \mathrm{cm}^{2}\right)$ & & oncentration \\
\hline$L_{f}$ & $\begin{array}{l}\text { Fracture length (length of 2D fracture or radius of } \\
\text { a penny-shaped fracture) }\end{array}$ & $\mu$ & $\begin{array}{l}\text { ted fluid viscosity to proppant } \\
\text { tion }\end{array}$ \\
\hline$h_{f}$ & Fracture height (m) & $\mu_{0}$ & Corrected fluid viscosity to proppant \\
\hline$E(k)$ & Complete elliptical ir & & \\
\hline$K(k)$ & Complete elliptical integral of the first kind & $n$ & Non-Newtonian fluid constant \\
\hline
\end{tabular}

Oladoyin Kolawole, doyin.kolawole@ttu.edu| ${ }^{1}$ Rock Mechanics Laboratory, Texas Tech University, 101 Terry Fuller Petroleum Engineering Research Building, Lubbock, TX 79415, USA. ${ }^{2}$ Bob L. Herd Department of Petroleum Engineering, Texas Tech University, 807 Boston Avenue, Lubbock, TX 79409, USA. 
$\gamma \quad$ Non-Newtonian fluid constant

$C_{f D} \quad$ Dimensional fracture conductivity

$k_{f}, k \quad$ Fracture and formation permeability, $\mathrm{md}$

$w \quad$ Fracture width (in)

$X_{f} \quad$ Fracture half-length (ft)

\section{Introduction}

The United States is the largest global crude oil producer according to U.S Department of Energy report [1]; the tight shale gas and tight oil formations in the Eagle Ford is among the top three contributors to this accomplishment. In 2008, the tight oil and shale gas from unconventional reservoirs accounted for $12 \%$ of U.S. total crude oil production and $16 \%$ of total U.S. gas production; but as recent as 2018 (Fig. 1), the tight oil and shale gas contributed $60 \%$ of U.S. total oil production, and $70 \%$ of total U.S. gas production respectively [2].

Hydraulic fracturing (fracking) process (Fig. 2) is currently the most effective conventional reservoir-stimulation method in the energy industry. Matrix stimulation designs and applications in tight reservoirs has been extensively discussed [3-5], as well as optimum conditions for companies to opt for a re-fracturing operation. Geographically weighted regression (GWR) [6] has been shown to be a resourceful data analytic approach in evaluating the effect of well stimulation parameters in

\section{A Monthly Dry Natural Gas Production}

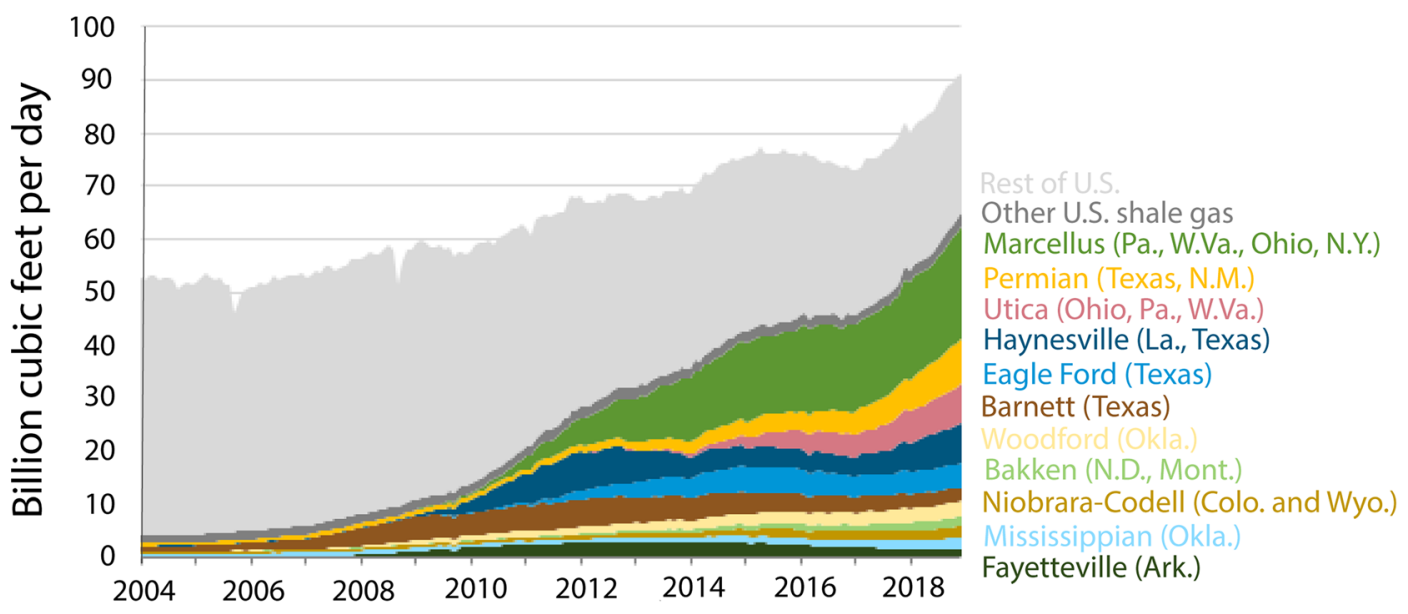

\section{B Monthly Crude Oil Production}

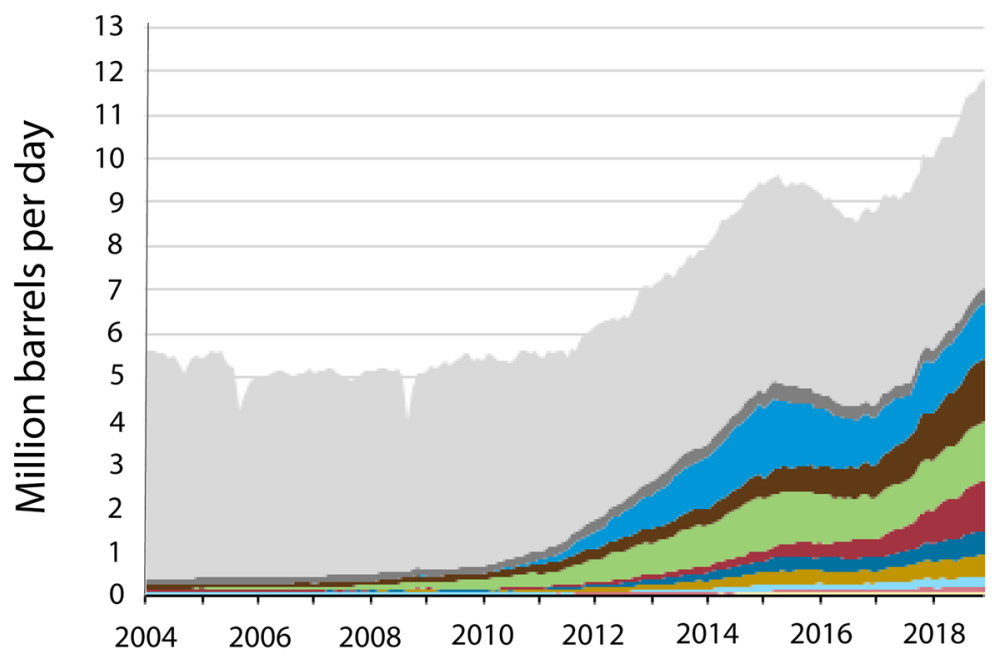

Other U.S. tight oil

Eagle Ford (Texas)

Spraberry (Texas Permian)

Bakken (N.D., Mont.)

Wolfcamp (Texas and N.M. Permian)

Bonespring (Texas and N.M. Permian)

Niobrara-Codell (Colo. and Wyo.)

Mississippian (Okla.)

Austin Chalk (La., Texas)

Fig. 1 Monthly U.S. production between 2004 and 2018: a dry natural gas; b crude oil. (After [2]) 
Fig. 2 Schematic description of multistage hydraulic fracturing process. $\sigma_{\mathrm{Hmax}}$ : maximum horizontal stress; $\sigma_{\mathrm{Hmin}}:$ minimum horizontal stress

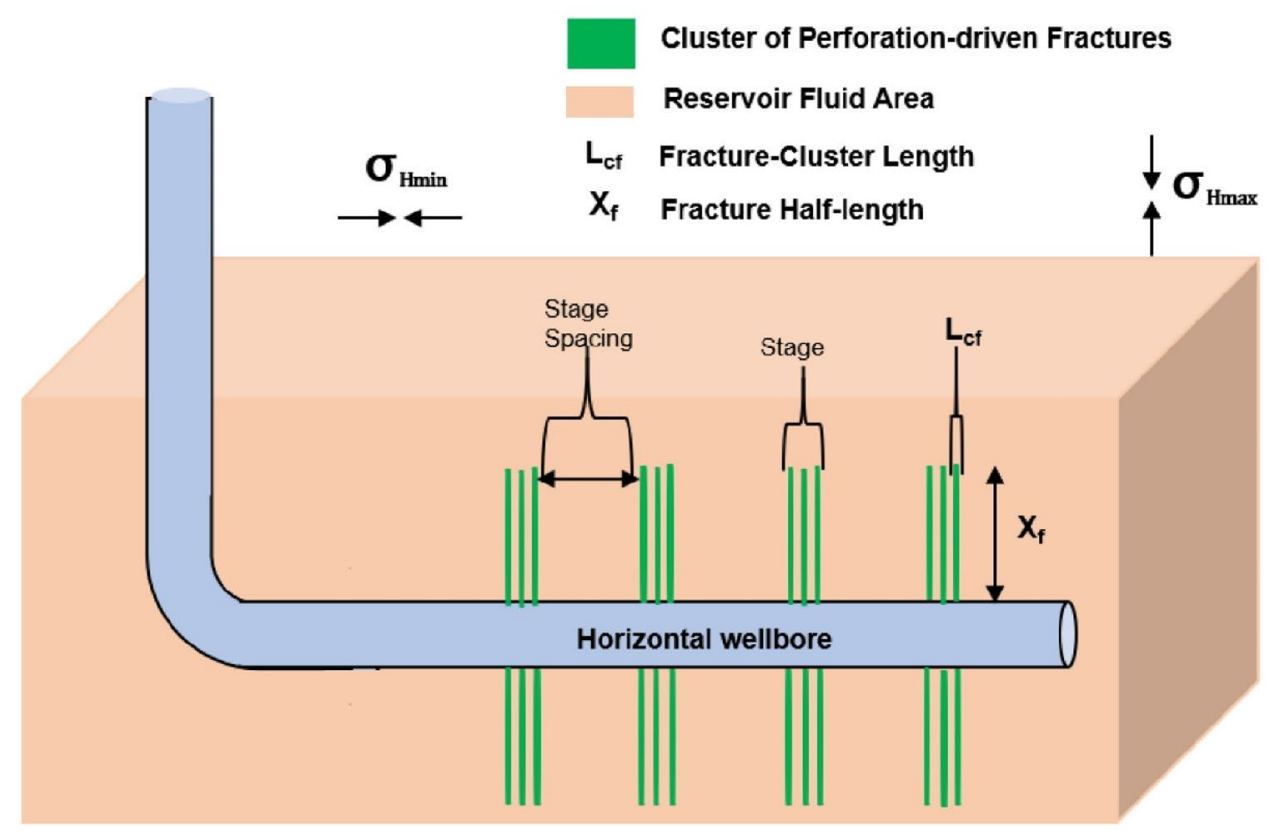

oil and gas production in unconventional wells. By virtue of technical and economical limitations of hydraulic fracturing technique in tight reservoirs, geothermal systems, and mining worldwide, optimized hydraulic fracturing design and application are critical for successful matrixstimulation operations. Hydraulic fracturing is a very complex technique, and it is still not fully understood till date. Furthermore, the number of stages, length of fracture clusters in each stage, proppant and fracturing fluid compatibilities, optimum spacing length, proppant transport and placement, proppant and frac-fluid compatibility, and optimum spacing are some of the challenges inhibiting successful application of this technique across the world [7-9]. In addition, the interactions between propagating hydraulic fractures and in-situ pre-existing natural fractures hinder successful hydraulic fracturing process, thereby and causing failure of the in-situ rock along its weakest plane. This complex fractomechanical behavior created during the intersection(s) between propagating hydraulic fractures (HF) and in-situ natural fractures (NF) is still being investigated till date. This problem was extensively addressed by Kolawole and Ispas [10], where the authors highlighted the commonly observed HF-NF interactions as arrest of propagating $\mathrm{HF}$ by the pre-existing natural fracture, propagating $\mathrm{HF}$ crossing the NF plane with or without dilation of natural fracture crossing, and NF-reactivation by dilation and/or shearing. They further emphasized that these fractomechanical behavior [11] can create 3 fracture networks groups (orthogonal, sub-orthogonal, linearto-sublinear), which will significantly impact the factures created during hydraulic fracturing process.
Herein, we define a "stage" as a cluster of nucleated fractures (Fig. 2), while "fracture-clusters" (cluster of perforation-driven fractures) consist of a number of perforation fractures, and "stage-spacing" is the distance between fracture-clusters. The nucleated fractures disturb the surrounding stress regime, thereby hindering the growth of other propagating fractures, and this disturbance is the "stress shadow" effect [12]. Quantitatively, in a transversely fractured horizontal well, stress shadowing is manifested as an increase in the in-situ stress parallel to the wellbore.

The proppant transport depends on the particle size, proppant density, and the fluid viscosity. Proper selection of proppant types and sizes is very important in hydraulic fracturing treatment because it influences the dimensions of the propagating fractures [13]. Cyclic changes in fracture closure stress due to well shut-ins, exerts some amount of stress on proppants resulting in the realignment of the proppant pack arrangement, and sometimes embedment. Proppant embedment is a phenomenon whereby the proppants gets buried in the fracture face and produces smaller particles (fines), and most times crushing the proppant due to the closure stress. The fracture geometry and conductivity are greatly impacted by fracture embedment. The authors observed that curable resin coated sand (CRCS) will have less fines production in comparison with uncoated frac sand (UFS) and lightweight ceramic (LWC) when tested at realistic downhole fracture condition with and/or without cycling. The authors conducted tests using ideal in-situ conditions such as fracture gradient of $\leq 1.1 \mathrm{psi} / \mathrm{ft}$, proppant weight between $300,000-400,000 \mathrm{lbm}$, pump injection rate between $80-100 \mathrm{bbl} / \mathrm{min}$, and slickwater frac fluid density 
between $0.1-2.2 \mathrm{ppg}$. At same 8500 psi closure stress and $275^{\circ} \mathrm{F}$, the results from 16 hydraulically-fractured Bakken wells shows that treatments with CRCS produced $27 \mathrm{lbm} /$ billion fines, the treatments with UFS produced $47 \mathrm{lbm} / \mathrm{bil}-$ lion fines, and the treatments with LWC produced $97 \mathrm{lbm} /$ billion fines. Likewise, after conducting cyclic stress tests, results of the percentage of proppants fines $<100$ mesh show that: (a) CRCS produced 0\% fines; (b) UFS produced $56.2 \%$ fines; (c) LWC produced $71.3 \%$ fines.

A similar result was observed with regards to proppant embedment. The settling velocity will increase as the diameter and density of the proppant agent increases, and the density and viscosity of the fracturing fluid decreases. As researchers, we always attempt to determine how best to improve the fracture fluid and enhance proppant behavior inside the fracture. In order to determine the best proppant for effective proppant transportation and placement, we considered the following: density difference between the fluid and the proppant, proppant specific gravity (S.G), proppant size, proppant type, proppant strength, proppant geometry and shape. The fracture behavior is often influenced by type of proppant used for a hydraulic fracture treatment. For a given size of proppant (20/40 mesh) and concentration $\left(2.0 \mathrm{lb} / \mathrm{ft}^{2}\right)$, a ceramic, bauxite, sand and resin coated sand will behave differently. A ceramic proppant is known to have better conductivity at a given closure stress than the other proppants. The only demerit to this, is the cost of this proppant. The ceramic proppant is very expensive, and appear to catalyze the decomposition of oxidizing breakers, speeding up the reduction of gel viscosity, and allowing faster settling of proppant. Resin-coated sands could also have similar effects and result in rapid settling. The strength of a proppant will play an important role in resisting embedment due to the closure stress. As the formation depth increases, we expect the closure stress to be higher. At a shallower formation, a low-strength proppant can be used since the effective stress on the proppant will not be sufficient to crush it.

The density of fracturing fluid affects the surface injection pressure and the flowback efficiency after the treatment. In low-pressure reservoirs, low-density fluids (foam) is effective in fluid cleanup. Conversely, in certain deep and geothermal reservoirs (including offshore frac-pack applications), higher density fracturing fluids (densities $>12 \mathrm{ppg}$ ) is required. The specific gravity of the proppant plays an important role in proppant transport. In Stoke's equation, the specific gravity (which correlates with density) will affect the proppant settling velocity inside the fracture. Hence, proppants with higher S.G are expected to settle faster. As a result, these proppants will not travel deep into the fractures when compared to lighter weight proppants that could travel much further.
So, the use of light weight and heavy weight proppants will affect the propped length of the hydraulic fracture. Similarly, the Stoke's law in relation to the settling of the proppant particle is a function of the square of the proppant size. As the size increases, we expect the particles to settle faster in the fracture. In another study [14, 15], the authors found out that particle physical size alone did not control settling. A straight line will indicate that only proppant diameter controls settling. However, as indicated by Stoke's law and observations from the non-linear, other factors will affect proppant settling in a fracture.

A portion of our results included in this study was first presented in Kolawole et al. [16] and Wigwe et al. [17]. In this study, we designed optimal hydraulic fracturing treatment, followed by investigating how proper selection and application of fracture treatment parameters influence hydraulic fracturing process by varying fracture cluster lengths, fracturing fluid types and viscosities, proppant types and densities, and fluid pump injection rates; utilizing data from 2 unconventional horizontal gas wells. Our investigation provides major insight into the impacts of varying fracturing treatment parameters for optimization of hydraulic fracturing process in unconventional reservoirs.

\subsection{Geologic Background}

The Eagle Ford shale, located in South-Western Texas, is a hydrocarbon-rich marl lying above Buda limestone, and is itself overlain by the Austin chalk [7]. The Eagle Ford shale configuration is made up of Cretaceous mudstone and carbonate, and they act as source rock for the overlaying Austin chalk. The Eagle Ford shale geographically is 400 miles in length, and 50 miles in width [18], with productive depths ranging from 2,500 to $14,000 \mathrm{ft}$, and a thickness of $120-350 \mathrm{ft}$ [19]. By virtue of low clay content and high carbonate content, tight oil and shale gas wells in Eagle Ford formations can be easily be stimulated through hydraulic fracturing treatment relative to other shale plays in comparison with other shale formations, due to its brittleness [20]. The Eagle Ford shale is interesting for single and multi-stage hydraulic fracturing because of the following characteristics: permeability ranging from 0.001 to $0.0001 \mathrm{md}$, porosity of $5-15 \%$, hydrocarbons ranging from dry gas through gas condensate through volatile oil to black oil, low Poisson's ratio, average Young's moduli, and low stress anisotropy. The Eagle Ford is commonly developed with horizontally perforated wells with multiple transverse fractures initiated along the lateral section $[7,11]$. 


\subsection{Governing mathematical models}

The Khristianovic-Geertsma-de Klerk (KGD) model [21, 22] and Perkins-Kern-Nordgren (PKN) model [23, 24] are the two most common 2-D hydraulic fracturing models. The energy required for hydraulic fracturing is dependent on the fluid pressure inside the propagating fracture, the relationship for a two-dimensional fracture (Eq. 1) and a penny-shaped fracture (Eq. 2) is given by Daneshy [25] as:

$p-\sigma=\sqrt{\frac{2 E \lambda}{\pi L_{f}\left(1-v^{2}\right)}}$

$p-\sigma=\sqrt{\frac{\pi E \lambda}{2 L_{f}\left(1-v^{2}\right)}}$

For a three-dimensional fracture, Daneshy [25] also presented the relationship as:

$p-\sigma=\sqrt{\frac{3 E \lambda}{2\left(1-v^{2}\right)} \times \frac{\left(L_{f}^{2}+h_{f}^{2}\right)[E(k)]^{2}}{L_{f}\left[2\left(L_{f}^{2}+h_{f}^{2}\right) E(k)-L_{f}^{2} K(k)\right]}}$

In Eq. 1 to Eq. 3, the propagating pressure (p) decreases as the fracture length $\left(X_{f}\right)$ increases, and as the propagating fracture grows larger, lower pressure will be required to sustain the propagation.

The Stoke's law on settling velocity for small particles $\left(R_{e}<2\right)$ [26]:

$V_{p s}=\frac{\left(\rho_{p}-\rho_{f}\right) g d_{p}^{2}}{18 \mu}$

In applying Stokes's law for proppant velocity, Gadde et al. [27] considered the proppant settling velocity for boundary effect (assuming large infinite fracture) and proppant particles interaction to give:

$V_{p s}^{\prime}=V_{p s}\left[0.563\left(\frac{d_{p}}{w}\right)^{2}-1.563\left(\frac{d_{p}}{w}\right)+1\right]\left(2.37 c^{2}-3.08 c+1\right)$

Gadde et al. [27] also expressed the influence of proppant concentration on frac fluid viscosity change as:

$\mu=\mu_{0}\left\{1+\left[0.75\left(e^{1.5 n}-1\right) e^{-\frac{\gamma(1-w)}{1000}}\right] \frac{1.25 c}{1-1.5 c}\right\}^{2}$

Recently, there has been a surge in developing and proposing new models to characterize the parent-child well fracture interference in unconventional reservoirs $[28,29]$. The "parent wells" are already-existing production wells, while the "child wells" are the new infill wells that have just been stimulated through hydraulic fracturing.
In Manchanda et al. [30], a 3D reservoir-scale poro-elastic geomechanics software (Multi-Frac) was utilized to model the production decline of the parent well and calculate its impact on the pressure, total stress and effective stress. Similarly, a fully coupled flow and geomechanics model was developed $[31,32]$ to the identify the poro-elastic behavior of multiphase-fluid diffusivity and rock deformation of interwell fracturing interference in Eagle Ford unconventional reservoirs, using finite-element method (FEM) and multifracture propagation using the displacement discontinuity method.

\section{Method and data}

In order to investigate the impact of fracture-cluster lengths, proppant types and sizes, frac fluid types, proppant densities, fluid viscosities, and injection rates on hydraulic fracturing design and treatment, we utilized data from 2 unconventional horizontal gas wells (Well 1 and Well 2). Well 1 is a horizontal gas well located in the Eagle Ford shale formation, while Well 2 is cased to a TVD of $11,300 \mathrm{ft}$ and located in a tight shaly sandstone formation in the Permian Basin. We then adopted 2D and 3D hydraulic fracturing simulation models available in StimPlan ${ }^{\mathrm{TM}}$ software developed by NSI Technologies, and FRACPRO $^{\mathrm{TM}}$ software developed by CARBO Ceramics Inc. We developed 5 cases studies for the analyses conducted in this study. We utilized data from Well 1 and the Stim$\mathrm{Plan}^{\mathrm{TM}}$ simulator for case studies 1-3, while data from data from Well 2 and the FRACPRO ${ }^{\text {TM }}$ simulator for case studies 4 and 5 . The merits of simulation models utilized for this study are: (1) The possibility for us to integrate petrophysical log data, geologic data, geomechanical data, drilling data, reservoir data, and production data into the design of hydraulic fracturing treatment. (2) The ability to conduct 2-D, pseudo 3-D, and full 3D simulations of the hydraulic fracturing treatment, and analyze the results. These simulation models can be useful in investigating fracture mechanisms, proppant transportation and placement, inter-fracture interferences, and parent-child well interferences. It is imperative to note that choice of simulation software utilized for the case studies did not influence the results presented in this study.

The most important input data for our models are the petrophysical log data. In recent studies, the mechanical properties of unconventional reservoir rock cuttings [33] can be evaluated to determine the orientation and magnitude of the in-situ stress, required for hydraulic fracturing design. Our optimized hydraulic fracturing approach utilized for this study is presented in Fig. 3.

For the hydraulic fracturing treatment in the first 3 case studies, we divided the treatment procedure into 3 tasks 
Fig. 3 Hydraulic fracturing design approach

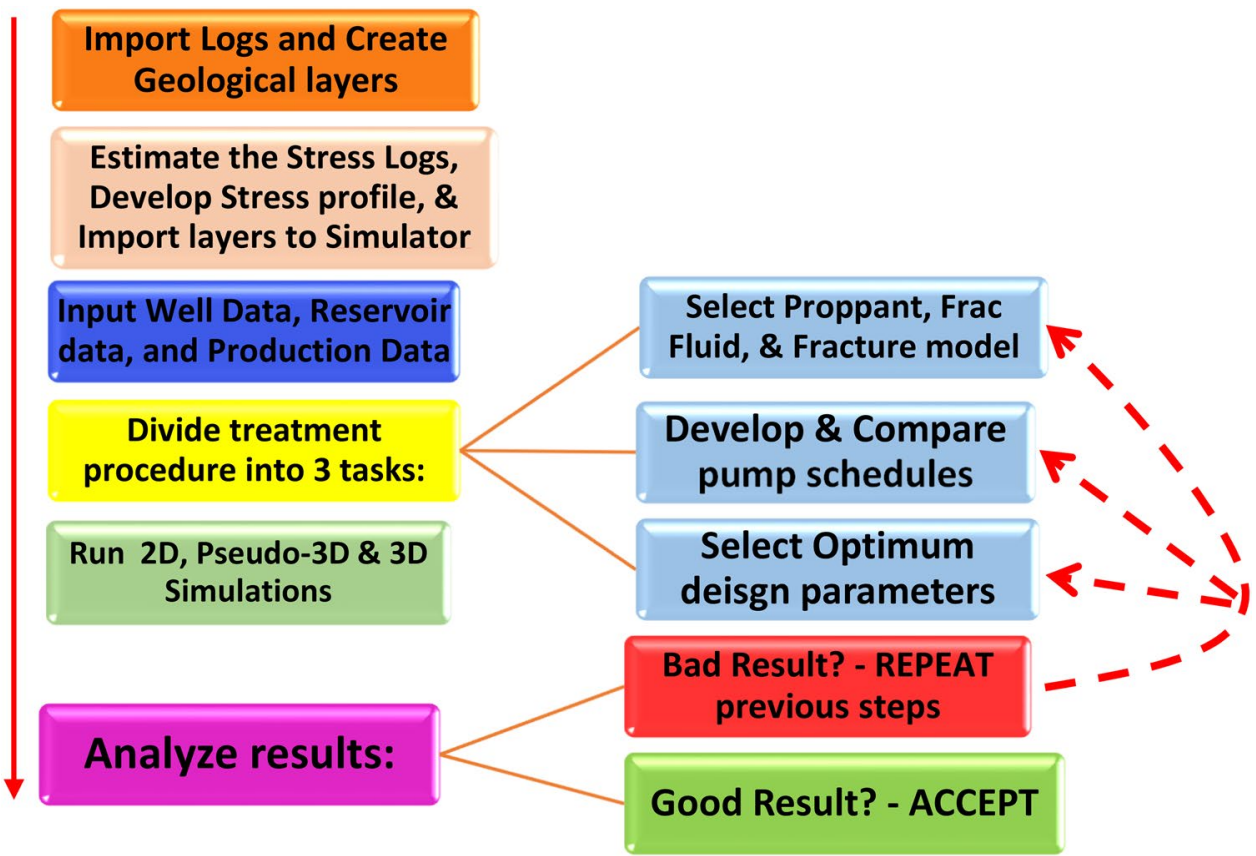

to determine the optimum treatment required for a deep and wide fracture with good fracture conductivity. For the first case study, we selected Slickwater as frac fluid and a 20-40 mesh sand as proppant. We then varied perforation-cluster lengths of $1 \mathrm{ft}, 3 \mathrm{ft}, 5 \mathrm{ft}, 7 \mathrm{ft}$, and $9 \mathrm{ft}$. In the second case study, we utilized a $40 \#$ Cross-link gel as frac fluid and a Northern white 30-50sand as proppant. In the third case study, we utilized a 20\# linear/40\# Cross-link as frac fluid; with Badger 100 mesh and RC sand PC 16-30 as proppants. The smaller the mesh size, the bigger the proppant size.

We created the geological layering in the zones of interest for Well 1 and Well 2, and the stress profile (Fig. 4) to determine the formation interval with the lowest in-situ stress to place our perforations before exporting our output logs to StimPlan ${ }^{\mathrm{TM}}$ and FRACPRO ${ }^{\mathrm{TM}}$. We then conducted 2D and 3D simulation analyses of our results.

The data we utilized for case studies 4 and 5 are presented in Tables 1,2,3,4. In our optimized hydraulic fracturing treatment schedule for the fourth and fifth case studies in FRACPRO ${ }^{\mathrm{TM}}$ software, we originally injected at 15 bpm, with the $5.4 \mathrm{cp}$ PurGel III. For rate diagnostics, we evaluated the fracture parameters at an injection rate of $10,13,15,20$, and 30 bpm leaving all other parameters constant (and fluid viscosity of $5.4 \mathrm{cp}$ ). We did this for the 1.9 and 3.5 specific gravities. We also did a fluid viscosity diagnostic study for both proppant types by varying the apparent viscosity of the fluid for 1, 5.4, 10 and $100 \mathrm{cp}$ using an injection rate of $13 \mathrm{bpm}$. This was the rate that gave the "optimum" fracture length in the rate sensitivity study. We will present the effect of both parameters on the original fracture length created and the propped length. We will also present its effect on propped width, height, dimensionless fracture conductivity, and injection pump horsepower.

\section{Results}

\subsection{Case study 1 (slickwater frac-fluid, 20-40 mesh sand proppant, and varying cluster lengths)}

The in-situ stress profile created is presented in Fig. 4. We developed 3 fracture-clusters with each having lengths of $1 \mathrm{ft}, 3 \mathrm{ft}, 5 \mathrm{ft}, 7 \mathrm{ft}$, and $9 \mathrm{ft}$; utilizing slickwater frac-fluid and 20-40 mesh sand proppant. We obtained 2D and 3D hydraulic fracture simulation results which includes fracture width profile (Fig. 5), and proppant volume fraction (Fig. 6). In Fig. 7, we presented the 3D simulation result of three $7 \mathrm{ft}$ fracture-clusters.

\subsection{Case study 2 (40\# cross-link gel, northern white $\mathbf{3 0 - 5 0}$ sand proppant, and varying cluster lengths)}

We developed 3 fracture-clusters using 40\# Cross-link gel as frac fluid and a Northern white 30-50 sand as proppant. We obtained 2D and 3D hydraulic fracture simulation results which includes fracture width profile (Fig. 8), and proppant volume fraction (Fig. 9). In Fig. 10, 


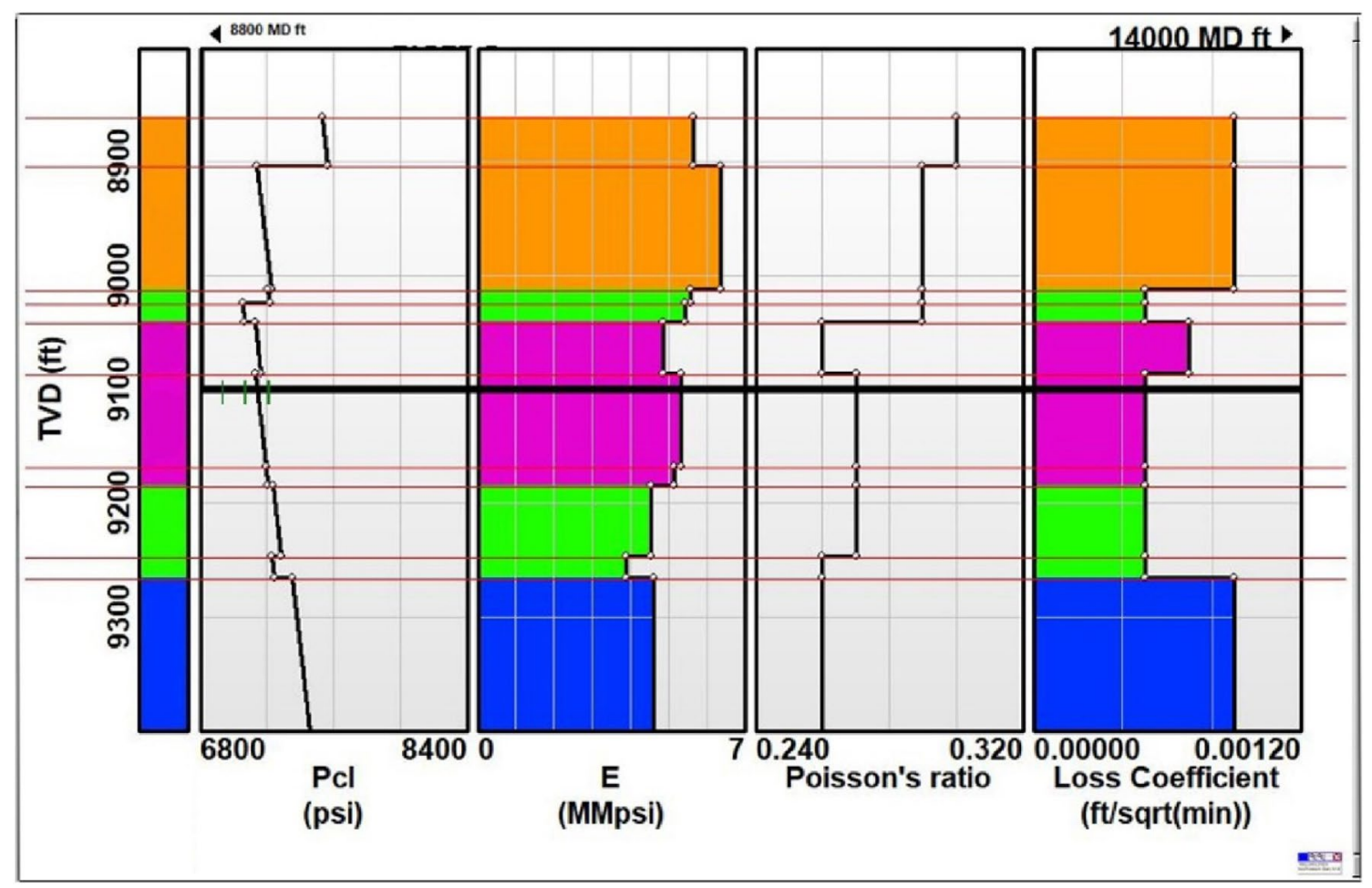

Fig. 4 In-situ stress profile developed for case study 1.[16]

Table 1 Formation properties at zone ff interest for well 2

\begin{tabular}{ll}
\hline Formation properties & Value \\
\hline Lithology & Shaly Sandstone \\
Depth, $\mathrm{ft}$ & $8208-8232$ \\
Thickness, $\mathrm{ft}$ & 24 \\
Stress, Psi & $5.417 \times 10^{3}$ \\
Young's Modulus, Psi & $3.56 \times 10^{6}$ \\
Poisson's Ratio & 0.23 \\
Fracture Toughness, psi. $\sqrt{ }(\mathrm{in})$ & 977 \\
Permeability, md & 0.1 \\
Leak-off Coefficient $\mathrm{ft} / \sqrt{ }(\mathrm{min})$ & $2.7316 \times 10^{-3}$ \\
Porosity & 0.17 \\
\hline
\end{tabular}

Table 2 Fluid properties for case studies 4 and 5

\begin{tabular}{lll}
\hline Fluid & WATER FRAC & PurGel III \\
\hline Initial viscosity $(\mathrm{cp})$ & 3.35 & 5.42 \\
Initial $\mathrm{n}^{\prime}$ & 1.00 & $8.29 \times 10^{-1}$ \\
Initial k' (lbf·s^n $\left./ \mathrm{ft}^{2}\right)$ & $7.00 \times 10^{-5}$ & $3.29 \times 10^{-4}$ \\
Viscosity @ 4.0 $\mathrm{h}(\mathrm{cp})$ & $3.91 \times 10^{-1}$ & 3.19 \\
\hline
\end{tabular}

we present the 3D simulation result of proppant volume fraction variation with time for $40 \#$ Cross-link gel frac fluid and Northern white 30-50 sand proppant.
Table 3 Simulation design for case studies 4 and 5

\begin{tabular}{lll}
\hline Fluid & WATER FRAC & PurGel III \\
\hline $\mathrm{n}^{\prime} @ 4.0 \mathrm{~h}$ & 1.000 & $8.14 \times 10^{-1}$ \\
$\mathrm{k}^{\prime} @ 4.0 \mathrm{~h}\left(\mathrm{lbf} \cdot \mathrm{s}^{\wedge} \mathrm{n} / \mathrm{ft}^{2}\right.$ ) & $8.158 \times 10^{-6}$ & $2.12 \times 10^{-4}$ \\
Base fluid Sp. gravity & 1.0000 & 1.01 \\
Spurt loss (gal/ft ${ }^{2}$ ) & $3.00 \times 10^{-2}$ & $2.50 \times 10^{-2}$ \\
Wall building (ft/min $1 / 2)$ & 0.003 & 0.003 \\
Flowrate \#1 (bpm) & 10.00 & 10.00 \\
Fric Press \#1 (psi/1000 ft) & 97.57 & 155.7 \\
Flowrate \#2 (bpm) & 20.00 & 25.00 \\
Fric Press \#2 (psi/1000 ft) & 278.2 & 598.0 \\
Flowrate \#3 (bpm) & 40.00 & 40.00 \\
Fric Press \#3 (psi/1000 ft) & 794.0 & 1194.5 \\
Well Friction Multiplier & 0.700 & 1.000 \\
\hline
\end{tabular}

\subsection{Case study 3 (20\# linear/40\# cross-link, badger 100 mesh sand and RC sand PC 16-30 as proppants)}

We developed 3 fracture-clusters using 20\# linear/40\# Cross-link as frac fluid with Badger 100 mesh sand and RC sand PC 16-30 as proppants. We obtained 2D and 3D hydraulic fracture simulation results which includes 
Table 4 Proppant properties for case studies 4 and 5

\begin{tabular}{lll}
\hline Proppant & CarboLite 20/40 & CarboLite 20/40 \\
\hline Proppant type & Low density & High density \\
Bulk dens (lbm/ft ${ }^{3}$ ) & 73.00 & 134.5 \\
Packed porosity & 0.384 & 0.384 \\
Specific gravity (S.G) & 1.90 & 3.5 \\
Turbulence coeff a & 1.10 & 1.10 \\
Turbulence coeff b & 0.098 & 1.000 \\
Diameter (in) & 0.029 & 0.029 \\
Perm @ 0 psi (D) & 500 & 500 \\
Perm @ 4000 psi (D) & 380 & 380 \\
Perm @ 8000 psi (D) & 320 & 320 \\
Perm @ 12000 psi (D) & 240 & 240 \\
Perm @ 16000 psi (D) & 185 & 185 \\
Perm @ 20000 psi (D) & 160 & 160 \\
\hline
\end{tabular}

fracture width profile (Fig. 11), and proppant volume fraction (Fig. 12).

\subsection{Case study 4 ( 13 bpm injection rate, $5.4 \mathrm{cp}$ apparent viscosity frac fluid, and 1.9 specific gravity proppant)}

With a stabilized injection rate of $13 \mathrm{bpm}$, frac fluid viscosity of $5.4 \mathrm{cp}$, and a low-density proppant (1.9 S.G), our result shows a $527 \mathrm{ft}$ fracture half-length, $464 \mathrm{ft}$ propped length, $97 \mathrm{ft}$ propped height, $0.172 \mathrm{in}$. average width closed on proppant, $1282 \mathrm{mD}$-ft average conductivity and the dimensionless fracture conductivity $\left(C_{\mathrm{FD}}\right)$ was 27.66 . Since the $C_{F D}$ is less than $300\left(C_{F D}<300\right)$, we expect a finite conductivity fracture. We observe almost a screen out at a net pressure of 1700 psi. The proppant distribution is shown in the fracture geometry profile (Fig. 13a), and the net pressure is shown in Fig. 13b. Greater proportion of the proppants was observed to concentrate at the center of the fracture, with the lowest concentration at the upper section, apparently due to gravity effect.

\subsection{Case study 5 (13 bpm injection rate, $5.4 \mathrm{cp}$ apparent viscosity frac fluid, and 3.5 specific gravity proppant)}

When the specific gravity (S.G) of the proppant was increase to 3.5 (for high-density proppant) and at the same stabilized injection rate and frac fluid viscosity, we observed contrasting results. The results showed a $520 \mathrm{ft}$ propped fracture length, $100 \mathrm{ft}$ propped height, and 0.091 propped average width. We observed a significant drop in the $C_{F D}$ from 27.66 in low-density proppant to 12.34 in high-density proppant. Wood et al. [34] conducted simulations using MFRAC comparing the
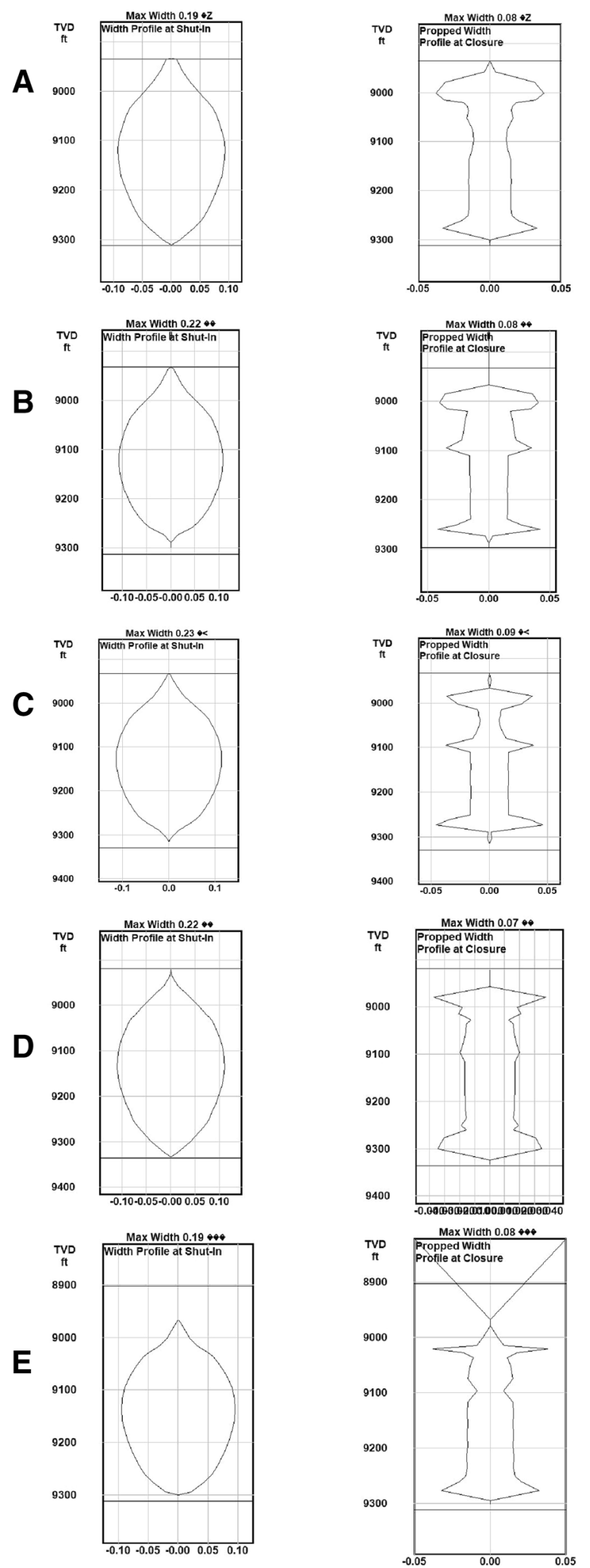

Fig. 5 Width profile at shut-in and closure for fracture-cluster lengths in case study 1: a $1 \mathrm{ft}$ b $3 \mathrm{ft}$ c $5 \mathrm{ft}$ d $7 \mathrm{ft}$ e $9 \mathrm{ft}$ 

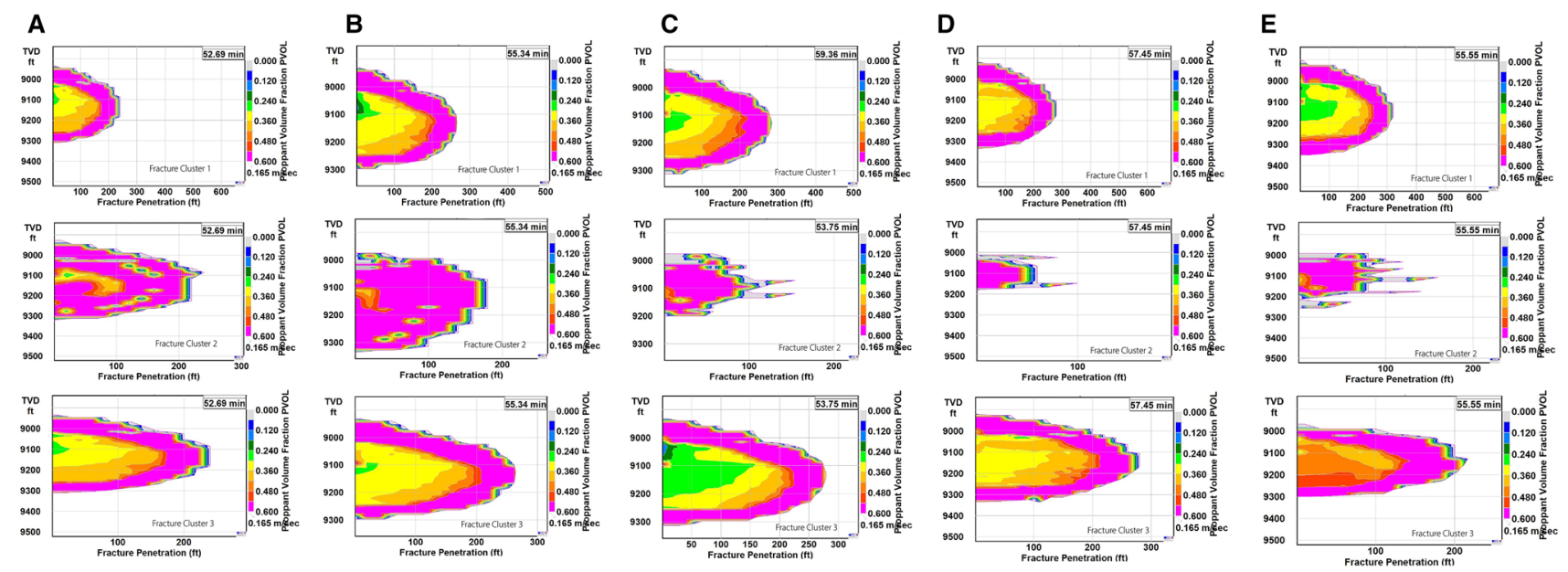

Fig. 6 Proppant volume fraction for cluster lengths in case study $1: \mathbf{a} 1 \mathrm{ft}$ b $3 \mathrm{ft}$ c $5 \mathrm{ft}$ d $7 \mathrm{ft}$ e $9 \mathrm{ft}$

Fig. 7 3D simulation of three $7 \mathrm{ft}$ fracture-clusters for case study 1

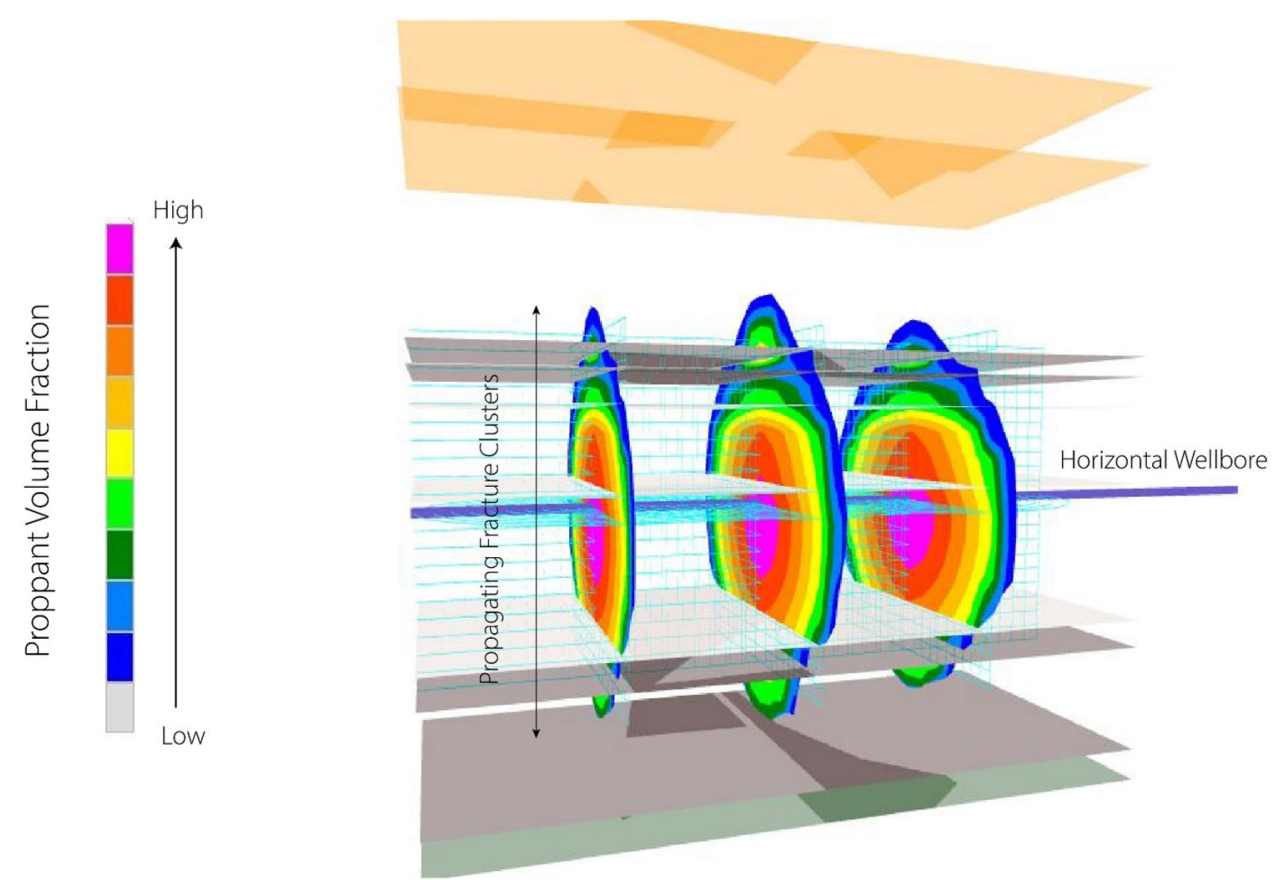

results for an ultra-light weight proppant with three different specific gravities and the 20/40 mesh size. Their work showed that the lighter-weight proppants were better placed in the zone of interest. In our study, we observe that the propped length increases with decreasing specific gravity. We expect a faster settling for the high-density proppant, which will be in accordance with Stoke's law given in Eq. (4). As a result, the high-density proppants will not travel far into the fracture, resulting in a shorter propped length and much wider fracture. Figure 14a shows the fracture geometry profile for the
3.5 specific gravity proppant, and Fig. 14b shows the net pressure.

The summary of numerical simulation results for case studies 4 and 5 are presented in Table 5 and Table 6.

\section{Discussion}

\subsection{Varying fracture-cluster lengths}

In case study 1, fracture-cluster lengths of $1 \mathrm{ft}, 3 \mathrm{ft}$, and $9 \mathrm{ft}$ provided the less fracture conductivities with an 
Stress (psi)

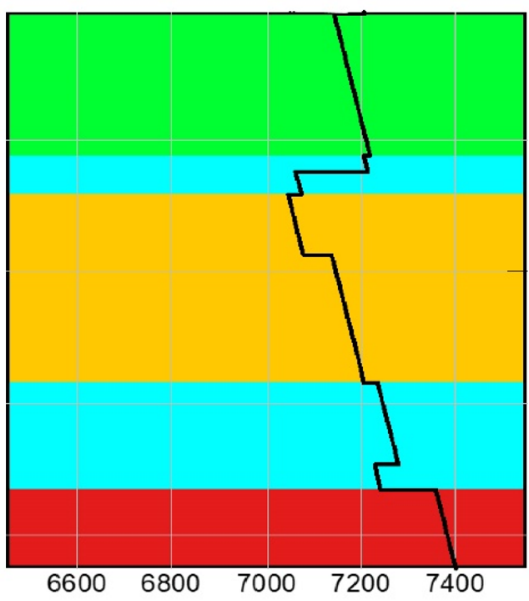

In-situ Stress Profile
Max Width $=0.29 \mathrm{ft}$

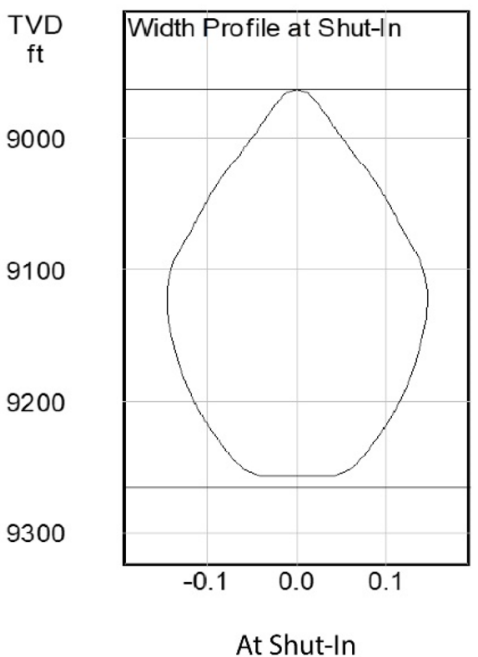

Max Propped Width $=0.19 \mathrm{ft}$

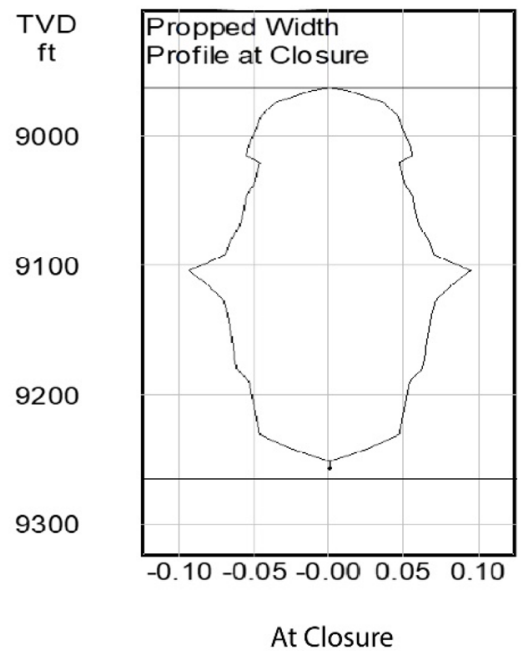

Fig. 8 In-situ stress profile, width profile at shut-in and at closure for case study 2
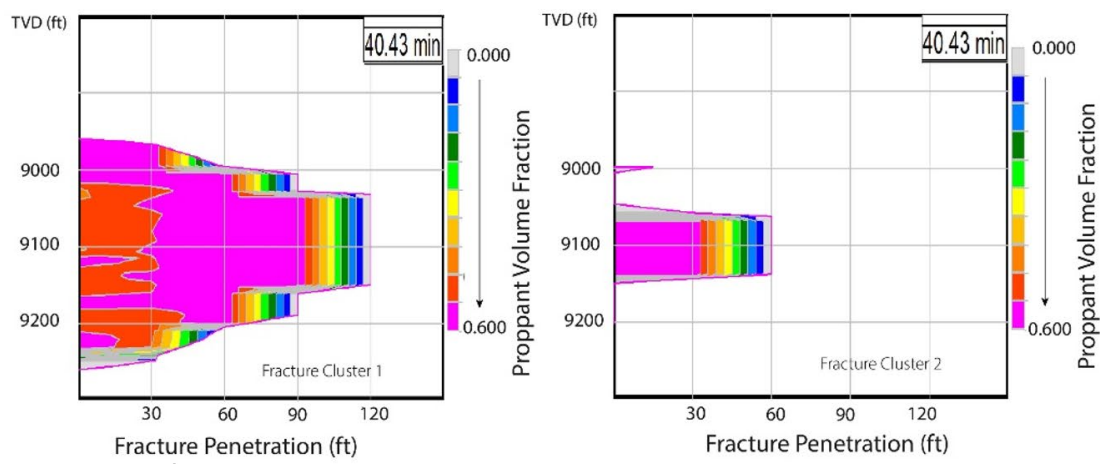

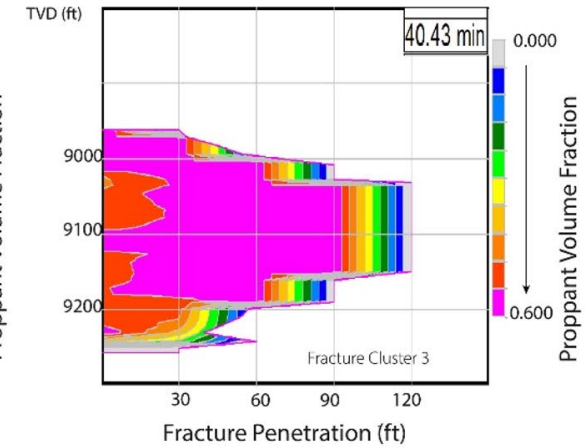

Fig. 9 Proppant volume fraction for case study 2

average of $1.9 \mathrm{mD}$-ft, $2.7 \mathrm{mD}$-ft, and $3.0 \mathrm{mD}$-ft respectively, in comparison to fracture-clusters of $5 \mathrm{ft}$ and $7 \mathrm{ft}$. The fracture-cluster lengths of $5 \mathrm{ft}$ and $7 \mathrm{ft}$ provided the greater fracture conductivities in the range of $3.5 \mathrm{mD}-\mathrm{ft}$ and $3.2 \mathrm{mD}$-ft respectively. We also observed fracturecluster lengths of $1 \mathrm{ft}, 3 \mathrm{ft}$ and $9 \mathrm{ft}$ creating lower stimulated reservoir volume (SRV) of $606 \mathrm{acre}-\mathrm{ft}, 702 \mathrm{acre}-\mathrm{ft}$, and 728 acre-ft respectively, in comparison to fractureclusters of $5 \mathrm{ft}$ and $7 \mathrm{ft}$. The fracture-cluster lengths of $5 \mathrm{ft}$ and $7 \mathrm{ft}$ provided higher stimulated reservoir volume (SRV) of 770 acre-ft and 790 acre-ft respectively. For this case study, the optimum fracture cluster lengths to achieve greater fracture conductivities and SRVs are $5 \mathrm{ft}$ and $7 \mathrm{ft}$.

Although 3 fracture-clusters were generated in our case 1 results presented in Figs 5,6,7, our observation from the results show that only the 1 st and 3 rd fracture-clusters propagated far enough to achieve a good fracture conductivity. At the start of the simulation, the fractures in the 3 clusters were growing simultaneously, until the 2 nd fracture-cluster was overshadowed by the 1st and 3rd fracture-clusters before it collapsed. This occurred repeatedly for all the fracture-clusters considered in case 1. Likewise, in the second and third case studies (Figs. 8,9,10,11,12), the three fracture-clusters propagated but only two fractures (1 and 3) grew further. This behavior was observed to be consistent in the first, second and third case studies. This due to stress shadowing and interference from the 1 st and 3 rd fracture-clusters on second fracture-cluster.

\subsection{Varying frac fluids and proppant sizes}

In the results (Figs. $8,9,10,11,12$ ) obtained from varying proppant sizes and frac fluids in cases 2 and 3, we 
Fig. $103 \mathrm{D}$ simulation of $3 \mathrm{~d}$ simulation of three fractureclusters for case study 2
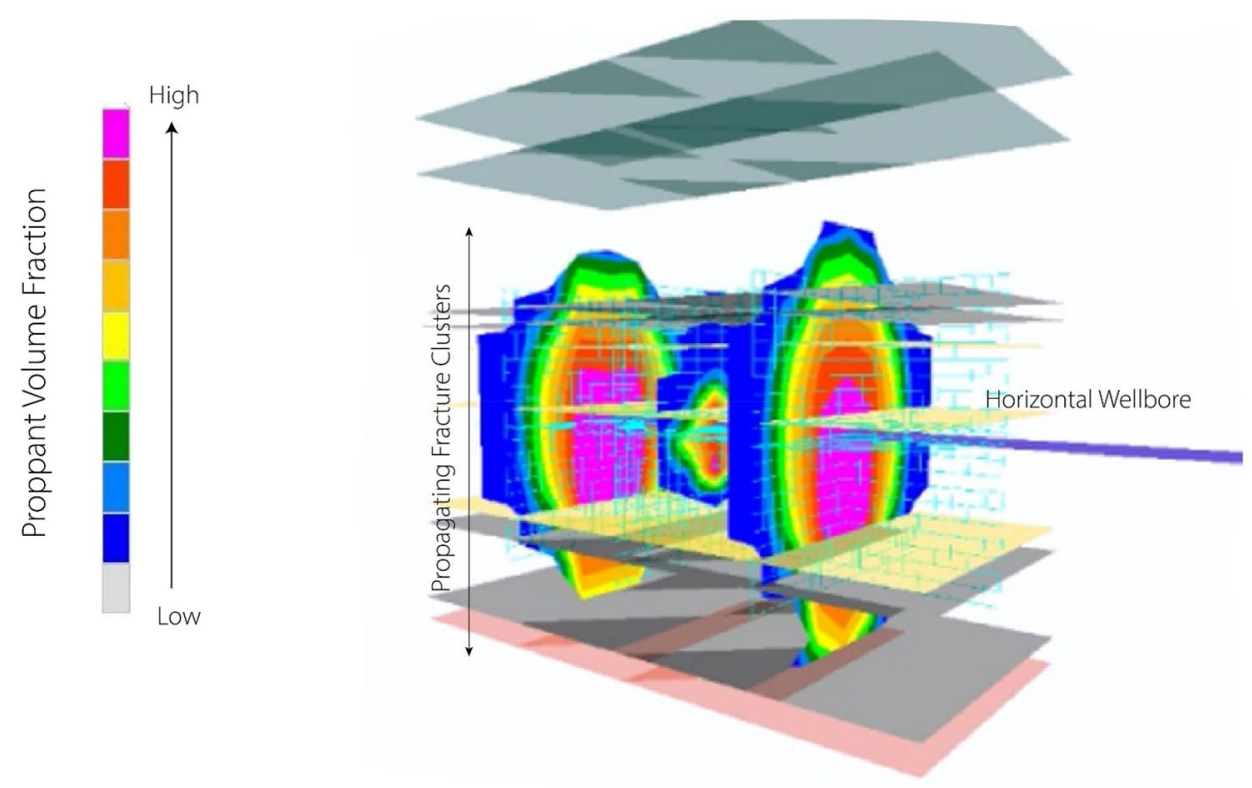

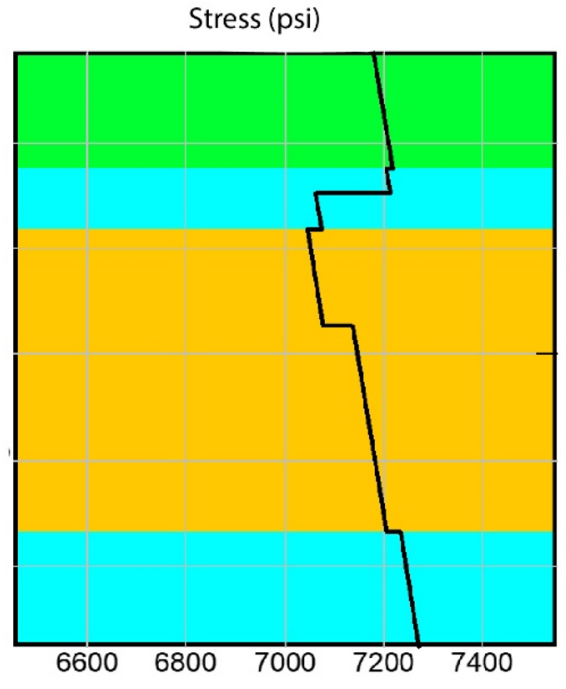

In-situ Stress Profile

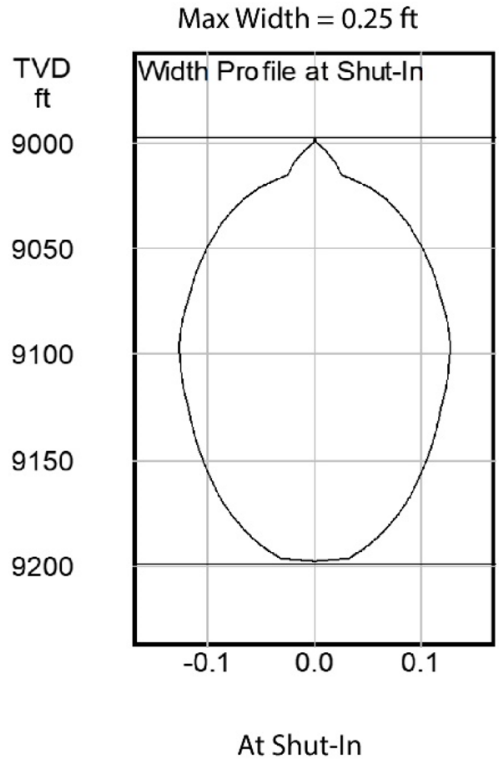

Max Propped Width $=0.21 \mathrm{ft}$

$\begin{gathered}\text { TVD } \\ \mathrm{ft} \\ 9000\end{gathered}$
9050
9100
9150
9200

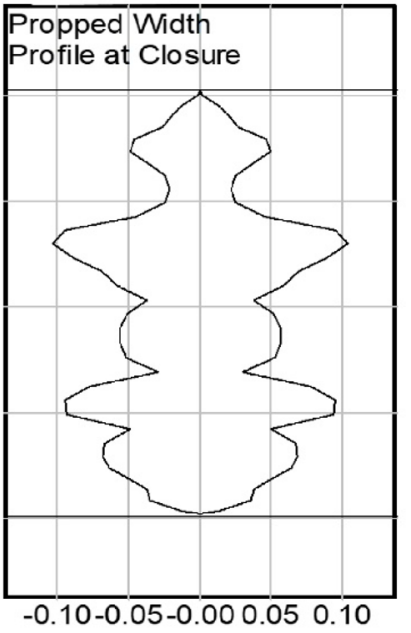

At Closure

Fig. 11 Stress profile and width profile at shut-in and closure for case study 3

observed that Northern White 30-50 proppant produced a lower fracture conductivity (average of $2.0 \mathrm{md}-\mathrm{ft}$ ) and fracture half-length (91 to $123 \mathrm{ft}$ ), in comparison with proppant composed of Badger 100 mesh and RC sand PC 16-30, which achieved a greater fracture conductivity (>3.0 md-ft) and fracture half-length (129-148 ft). The propped fracture width at closure in case study 2 was $0.19 \mathrm{ft}$ (Fig. 8), while the propped fracture width at closure in case study 3 was $0.21 \mathrm{ft}$ (Fig. 11). This was achieved due to the selected proppant configuration in case study 3 (Badger 100 mesh sand and RC sand PC 16-30) providing a higher conductivity than the proppant selected in case study 2 (Northern white $30-50$ sand). Since our stress profiles developed for case studies 2 (Fig. 8) and 3 (Fig. 11) showed closure stresses for both case studies to be significantly higher than $5000 \mathrm{psi}$, we expect the use of Northern white $30-50$ sand to be inefficient as a proppant material. The proppant selection for this high closure stress formation should be strong enough to keep the fractures opened. Consequently, the Resin Coated Sand (RC) introduced to the proppant configuration utilized for Case study 3 , provided the proppants with higher strength and 

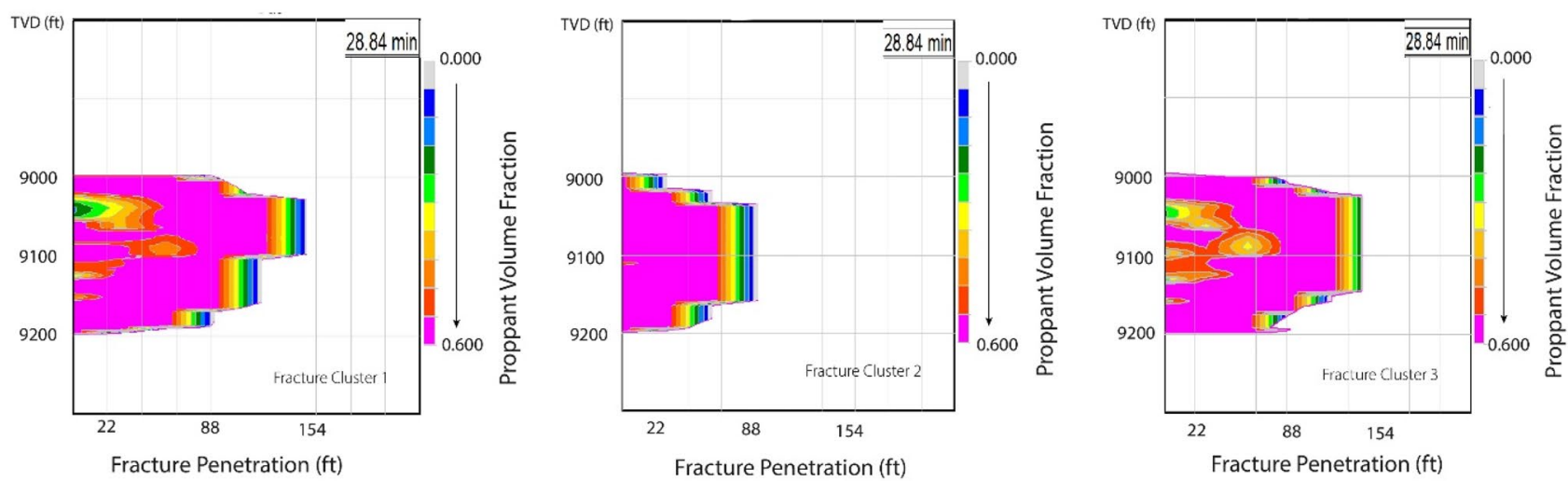

Fig. 12 Proppant volume fraction for case study 3

maximized fracture porosity and permeability than the proppant used in case study 2 . Therefore, the treatment parameters in case study 3 will provide our well stimulation design with optimum SRVs and hydrocarbon recovery than in case study 2.

\subsection{Effect of pump injection rate on fracture and propped length}

Figure 15 shows a plot of the effect of injection rate on the fracture and propped length for both proppants. We observe that both the fracture and propped lengths for the 3.5 S.G cases are higher than those of the 1.9 S.G. The fracture length increases with injection rate until $13 \mathrm{bpm}$. After $13 \mathrm{bpm}$, there is no appreciable increase in fracture length until $20 \mathrm{bpm}$ when increasing the rate results in a negative effect on fracture length. For the propped length, for both cases, it increased to a maximum at $13 \mathrm{bpm}$ and starts decreasing. We conclude that for an optimum fracture length to be created in the given scenario, the recommended injection rate to use is $13 \mathrm{bpm}$. We also observe the largest difference in propped length for both cases at this rate $(56 \mathrm{ft})$.

Since the formation has very low permeability $(0.1 \mathrm{md})$, the creation of long hydraulic fracture is of great importance for economic production. As a result, we decided to carry out further studies using the $13 \mathrm{bpm}$ optimum rate. The pump horsepower requirement for the given propped length generated is directly tied to economics. The more the horsepower required, the more expensive the hydraulic fracturing operation, and more pumps will be needed to create a given propped length as shown in Fig. 16. We observe that greater pump horsepower is needed to create $1 \mathrm{ft}$ of propped length using the 1.9S.G proppant than the 3.5 S.G.

\subsection{Effect of pump injection rate on dimensionless fracture conductivity}

Figure 17 shows the effect of pump injection rate on dimensionless fracture conductivity $\left(\mathrm{C}_{\mathrm{FD}}\right)$ for both lowand high-density proppants. Since formation permeability stays constant at $0.1 \mathrm{md}$ for all cases, we expect the dimensionless fracture conductivity to decrease with increasing length. This further implies that the 3.5 specific gravity case will have a lower $C_{f D}$ because it has the longer fracture length. In addition, from our discussion in the section above, since the $13 \mathrm{bpm}$ rate produced the largest fracture length, it follows that it will generate the lowest dimensionless conductivity. We observe (Fig. 17) that the $\mathrm{C}_{\mathrm{fD}}$ decreases from the largest value at a $10 \mathrm{bpm}$ to a lowest at $13 \mathrm{bpm}$. Afterwards we observe an increase in $C_{\mathrm{fD}}$ up to the $30 \mathrm{bpm}$ rate.

\subsection{Effect of pump injection rate on propped fracture geometry}

Figure 18a shows the propped fracture height as a function of the injection rate for both high- and low-density proppants. For all rates, except $20 \mathrm{bpm}$, the 3.5 S.G generated greater propped height than the 1.9 S.G. In general, we observe that the fracture height increases with injection rate. The minimum height obtained was about $91 \mathrm{ft}$, which is over four times the formation height. This implies that fracture grows into adjacent layers. The injection rate and specific gravity also had some effect on the width of the fracture. Figure $18 \mathrm{~b}$ shows the variation of propped fracture width with pump injection rate. The profile corresponds to the $C_{F D}$ discussed previously. We see a larger width for $10 \mathrm{bpm}$ rate, which reduced as rate increased to $13 \mathrm{bpm}$. Then we see increment in width for higher rates. Wider fracture should be expected as injection rate 


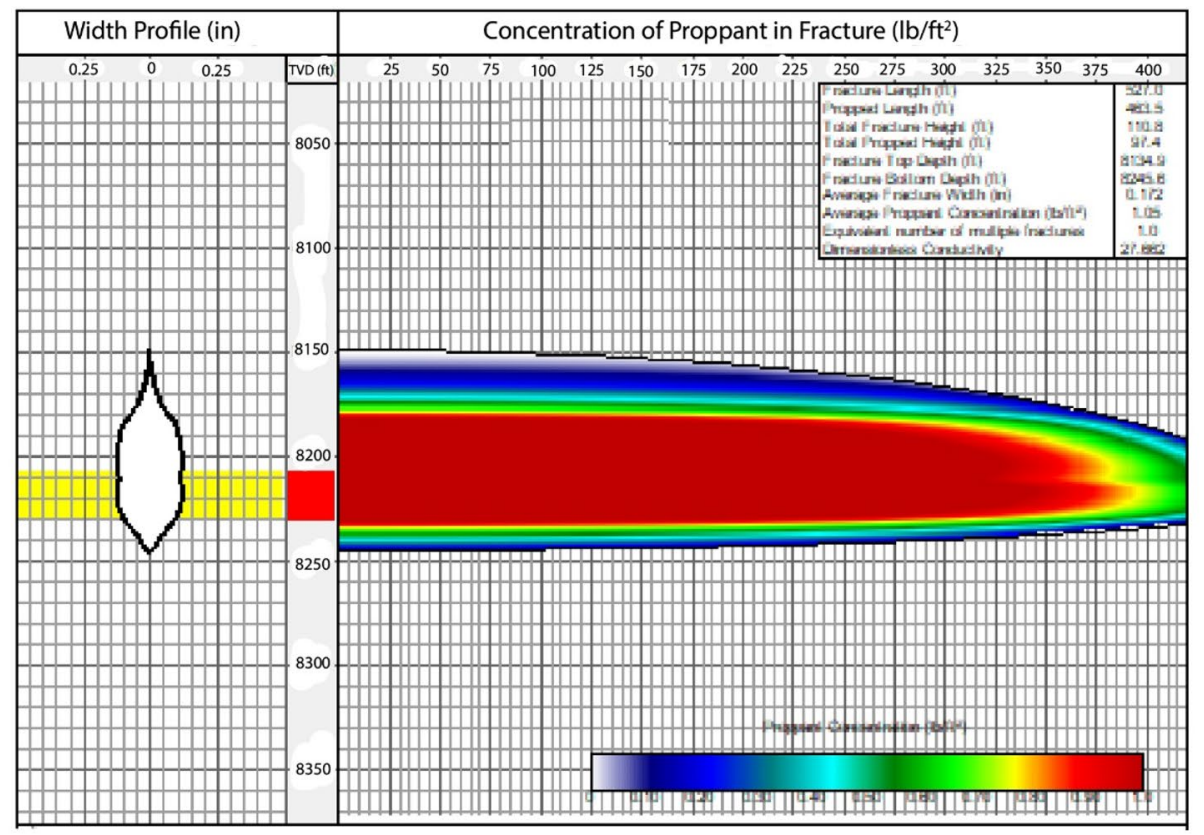

\section{A \\ Fracture Geometry \\ Profile at $13 \mathrm{bpm}$ \\ pump Injection rate \\ $5.4 \mathrm{cp}$ frac fluid \\ viscosity, and 1.9 \\ Specific Gravity \\ proppant}

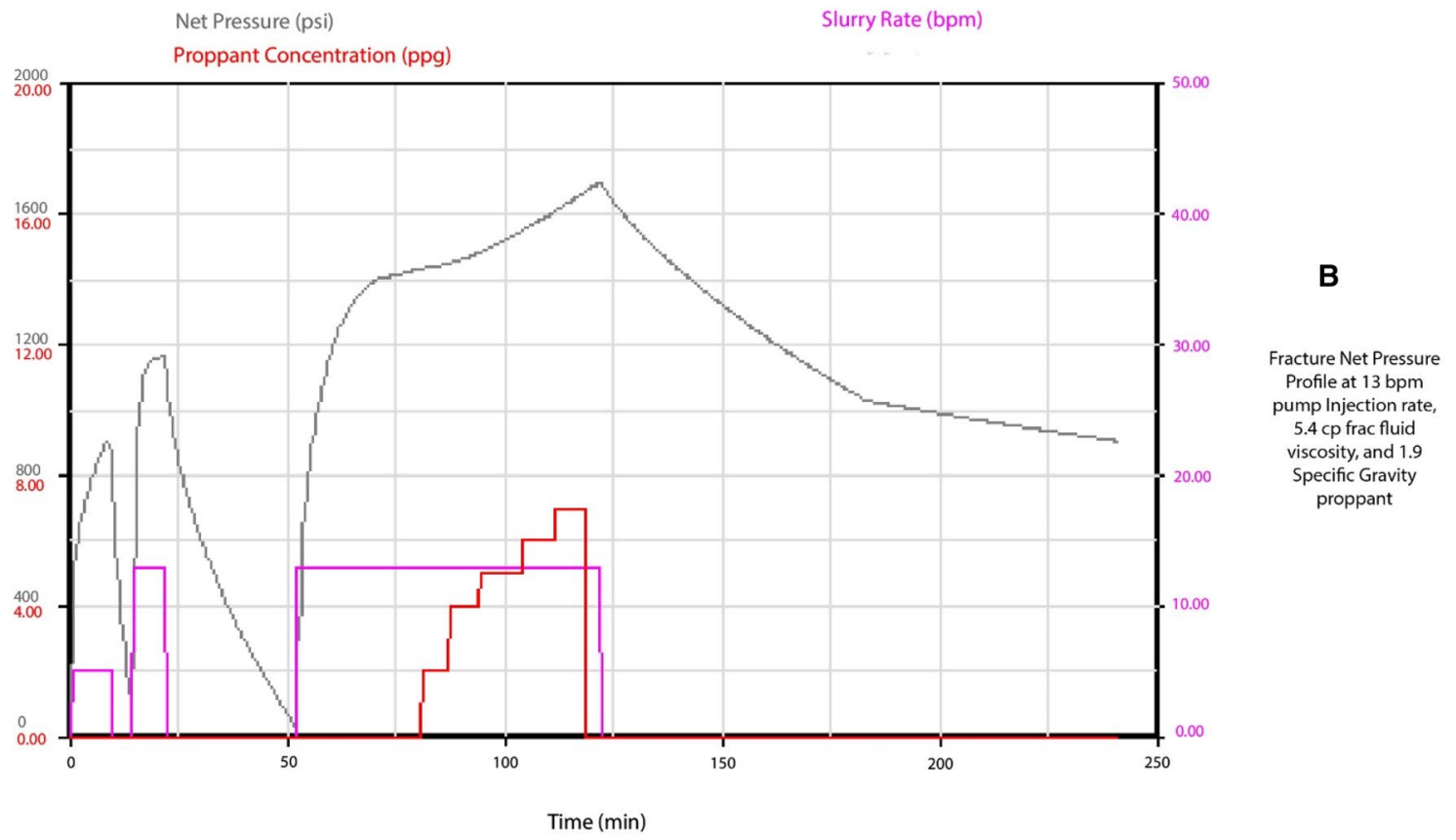

Fig. 13 At 13 bpm pump injection rate, $5.4 \mathrm{cp}$ frac-fluid viscosity, and 1.9 specific gravity proppant for case study 4: a fracture geometry profile; b fracture net pressure profile

increases, which was observed from $13 \mathrm{bpm}$. However, we see a much wider fracture at $10 \mathrm{bpm}$. This could be because fracture length has more effect on $C_{f D}$ than does width, its lower fracture length results in a higher $C_{\mathrm{fD}}$. It is also possible that because of the lower rate, the proppant settling resulted in a better packing and more uniform distribution which helped in creation of a larger width at the end of the job. The 1.9 specific gravity proppant had better width for all rates.

Our observations from Fig. 19 shows that the fractures grew more than the $3 \mathrm{ft}$ shale section into an uppersandstone layer. However, the shale section above this sandstone layer prevented fractures from further height propagation due to its thickness. The fractures did not grow into the lower formation because of a $20 \mathrm{ft}$ shale 


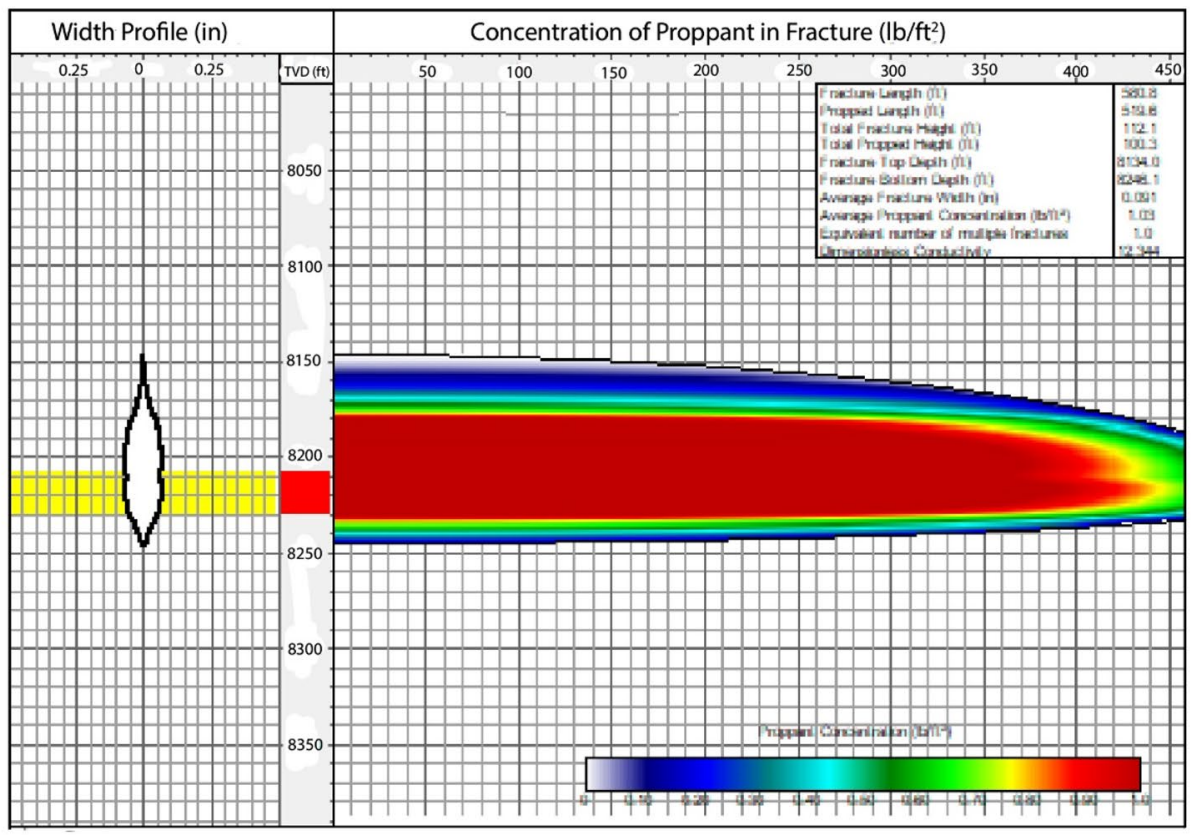

A

$$
\begin{gathered}
\text { Fracture Geometry } \\
\text { Profile at } 13 \mathrm{bpm} \\
\text { pump Injection rate, } \\
5.4 \mathrm{cp} \text { frac fluid } \\
\text { viscosity, and } 3.5 \\
\text { Specific Gravity } \\
\text { proppant }
\end{gathered}
$$

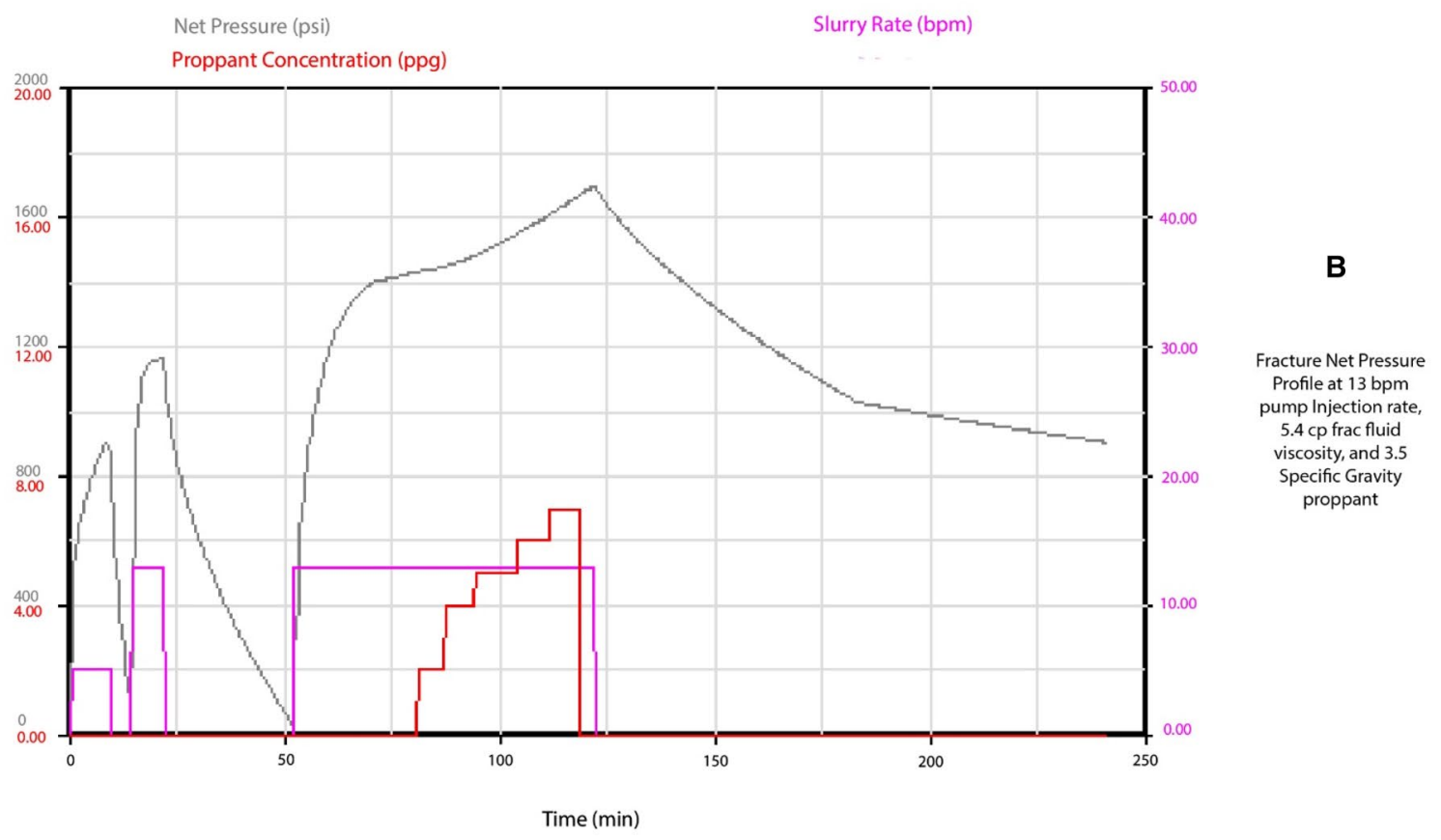

Fig. 14 At $13 \mathrm{bpm}$ pump injection rate, $5.4 \mathrm{cp}$ frac-fluid, and 3.5 specific gravity proppant for case study 5: a fracture geometry profile; b fracture net pressure profile

layer that confined the fracture growth. Therefore, our observation shows the shale above the upper sandstone and that below the target formation confining its height growth. This confinement can be attributed to the stress contrast between the sandstone and shale layers, in addition to the thickness of the barriers.

\subsection{Effect of fracturing fluid viscosity on fracture parameters}

Using the $13 \mathrm{bpm}$ as our best rate, we performed viscosity sensitivity analysis. For both $C_{F D}$ and propped length, there seem to be no significant effect of viscosity on the fracture parameters (Fig. 20a). 
Table 5 Summary of hydraulic fracturing simulation results for 1.9 specific gravity proppant

Proppant specific gravity=1.9; frac fluid viscosity, $\mu=5.42 \mathrm{cp}$; Carbolite 20/40 proppant

\begin{tabular}{llllllllll}
\hline Rate (bpm) & $\begin{array}{l}\text { Fracture half- } \\
\text { length (ft) }\end{array}$ & $\begin{array}{l}\text { Effective } \\
\text { propped } \\
\text { length }\end{array}$ & Avg. $\mathrm{HP}$ & $\mathrm{hp} / \mathrm{X}_{\mathrm{f}}$ & $\mathrm{C}_{\mathrm{FD}}$ & $\mathrm{h}(\mathrm{ft})$ & $\begin{array}{l}\text { Propped } \\
\text { height (ft) }\end{array}$ & Max width (in.) & Width closed (in.) \\
\hline 10 & 456 & 392 & 1010 & 2.349 & 36.6 & 97 & 91 & 0.33 & 0.199 \\
13 & 527 & 407 & 1537 & 3.313 & 27.66 & 111 & 97 & 0.27 & 0.172 \\
15 & 530 & 395 & 1956 & 4.366 & 28.22 & 116 & 98 & 0.26 & 0.177 \\
20 & 529 & 372 & 3270 & 7.88 & 30.08 & 126 & 99 & 0.24 & 0.19 \\
30 & 507 & 337 & 7171 & 19.54 & 34.09 & 142 & 103 & 0.22 & 0.207 \\
\hline
\end{tabular}

Table 6 Summary of hydraulic fracturing simulation results for 3.5 specific gravity proppant

Proppant specific gravity $=3.5$; frac fluid viscosity, $\mu=5.42 \mathrm{cp}$; Carbolite 20/40 proppant

\begin{tabular}{lllllllrlc}
\hline Rate (bpm) & $\begin{array}{l}\text { Fracture half- } \\
\text { length (ft) }\end{array}$ & $\begin{array}{l}\text { Effective } \\
\text { propped } \\
\text { length }\end{array}$ & Avg. HP & $\mathrm{hp} / \mathrm{X}_{\mathrm{f}}$ & $\mathrm{C}_{\mathrm{FD}}$ & $\mathrm{h}(\mathrm{ft})$ & Propped H (ft) & Max width (in.) & Width closed (in.) \\
\hline 10 & 502 & 386 & 1073 & 2.259 & 16.98 & 99 & 93 & 0.19 & 0.108 \\
13 & 581 & 390 & 1442 & 2.773 & 12.34 & 112 & 100 & 0.15 & 0.091 \\
15 & 586 & 381 & 1847 & 3.694 & 12.71 & 117 & 100 & 0.15 & 0.096 \\
20 & 589 & 363 & 3125 & 6.749 & 13.61 & 125 & 98 & 0.14 & 0.105 \\
30 & 552 & 332 & 6940 & 17.39 & 16.45 & 142 & 103 & 0.12 & 0.116 \\
\hline
\end{tabular}

Fig. 15 Effect of injection rate on fracture length and propped length

\section{Fracture Length vs Pump Injection Rate}

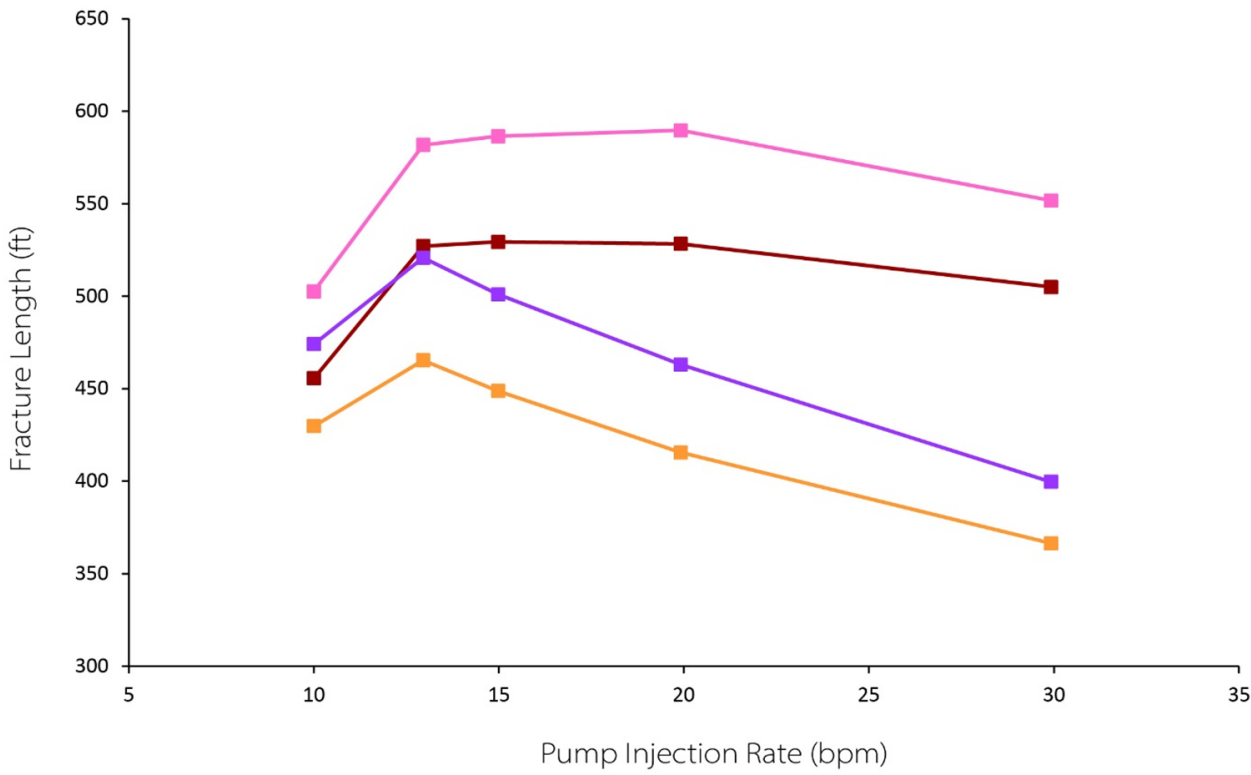

Fracture Length for 3.5 S.G
Proppant Fracture Length
for $1.9 \mathrm{~S} . \mathrm{G}$ for 1.9 S.G
Proppant Propped Length for 3.5 S.G
Proppant Propped Length for 1.95 .6 Proppant 
Fig. 16 Effect of pump horsepower and injection rate on propped length
Pump Power per $1 \mathrm{ft}$. Propped Length vs Pump Injection Rate

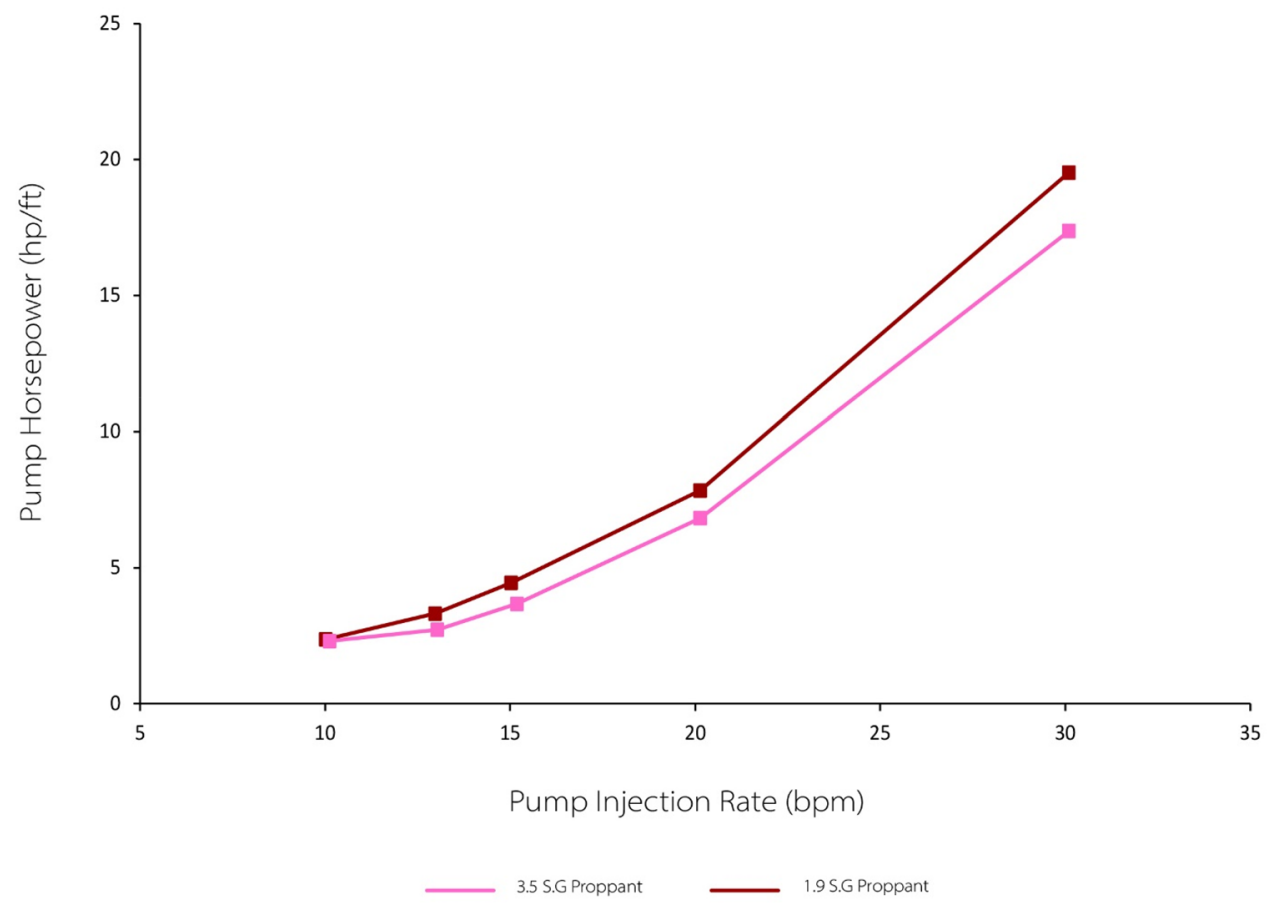

Pump Power per $1 \mathrm{ft}$. Propped Length vs Pump Injection Rate

Fig. 17 Effect of pump injection rate on dimensionless fracture conductivity

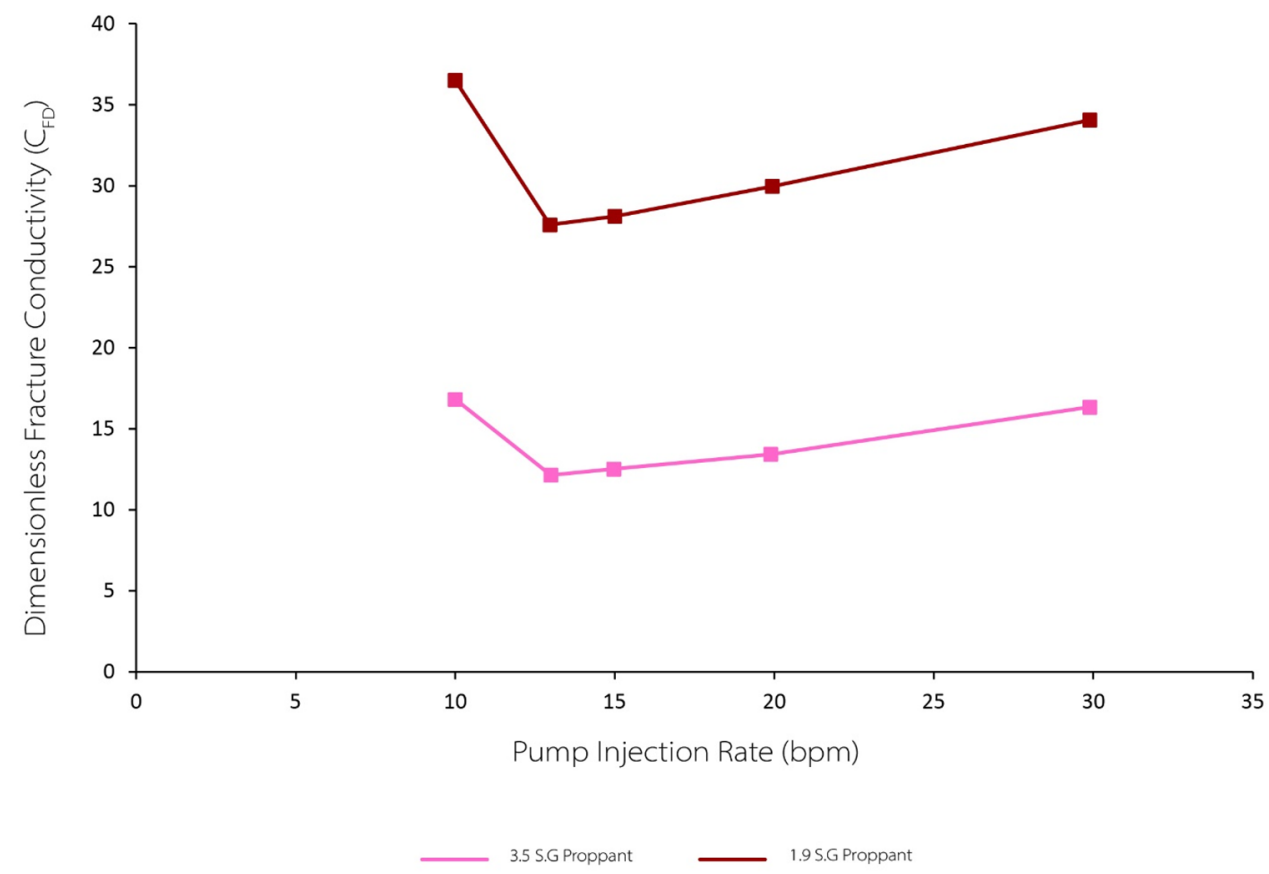

For example, the maximum change in $\mathrm{C}_{\mathrm{FD}}$ for the 1.9 proppant was less than 0.6 as viscosity was varied from 1 to $100 \mathrm{cp}$. For the 3.5 proppant, this difference was even less (0.25). As a result, we could infer that although viscosity do have an effect on fracture parameters, the result indicates that $C_{F D}$ is insensitive to effects of viscosity for

\section{SN Applied Sciences}


Fig. 18 Effect of pump injection rate on propped fracture geometry: a height; $\mathbf{b}$ width
Effect of Pump Injection Rate on Propped Fracture Geometry
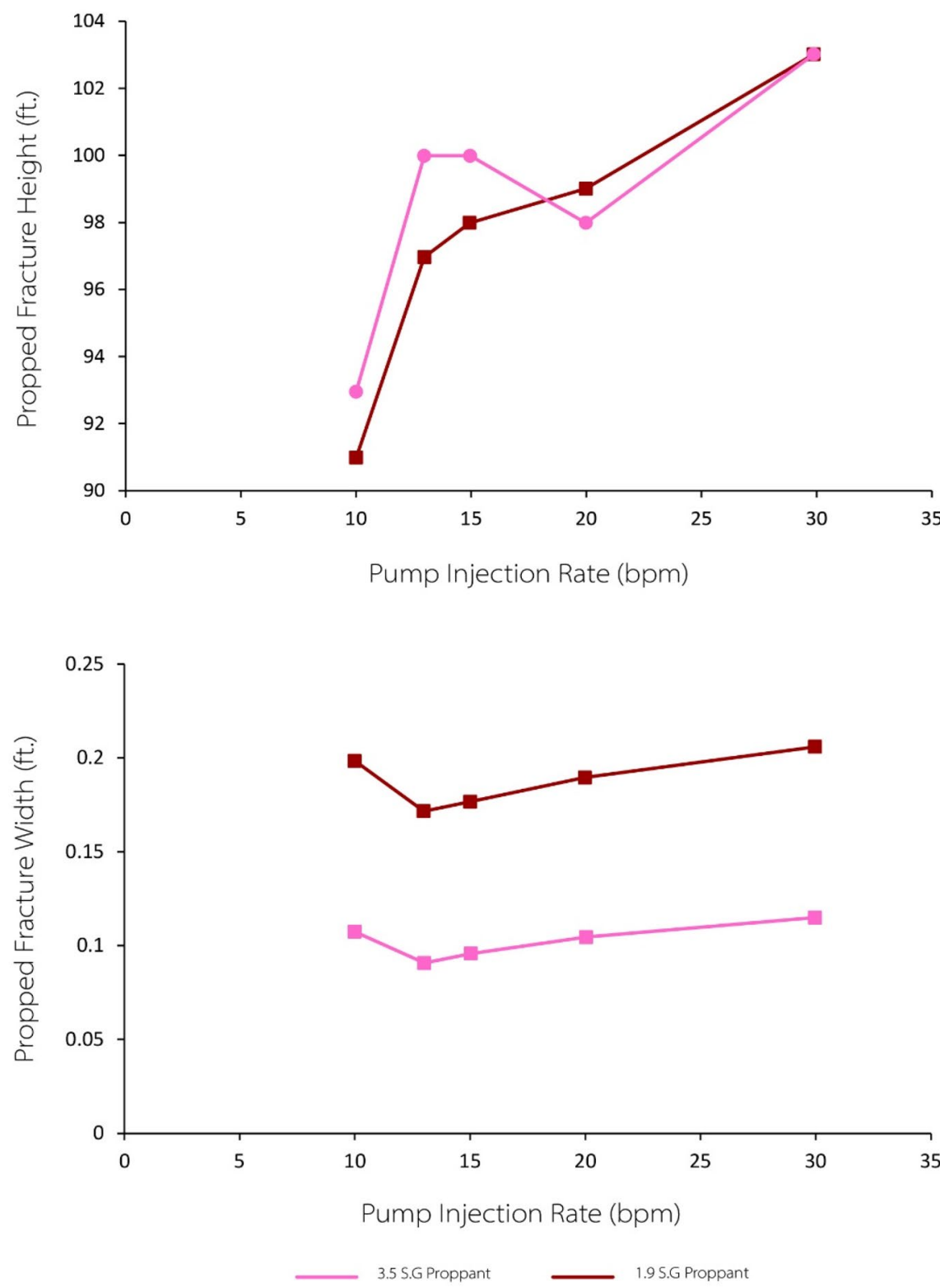

the case under consideration. The effect of viscosity on propped length is also insignificant (Fig. 20b). Similar to the $C_{f D}$ case, the maximum change in propped length for the range of viscosity simulated was less than $7 \mathrm{ft}$ for both cases. This is unlike the rate sensitivity analysis where this change was as high as $57 \mathrm{ft}$. The width stays constant as well as the height.

\subsection{Effect of pump injection rate on effective propped length}

On a closer look at the report generated from the simulation runs we observed a record for effective propped length. We plotted this data as shown in Fig. 21. Unlike the general observation in the entire simulation for frac and propped length, we can see that the 1.9 specific 


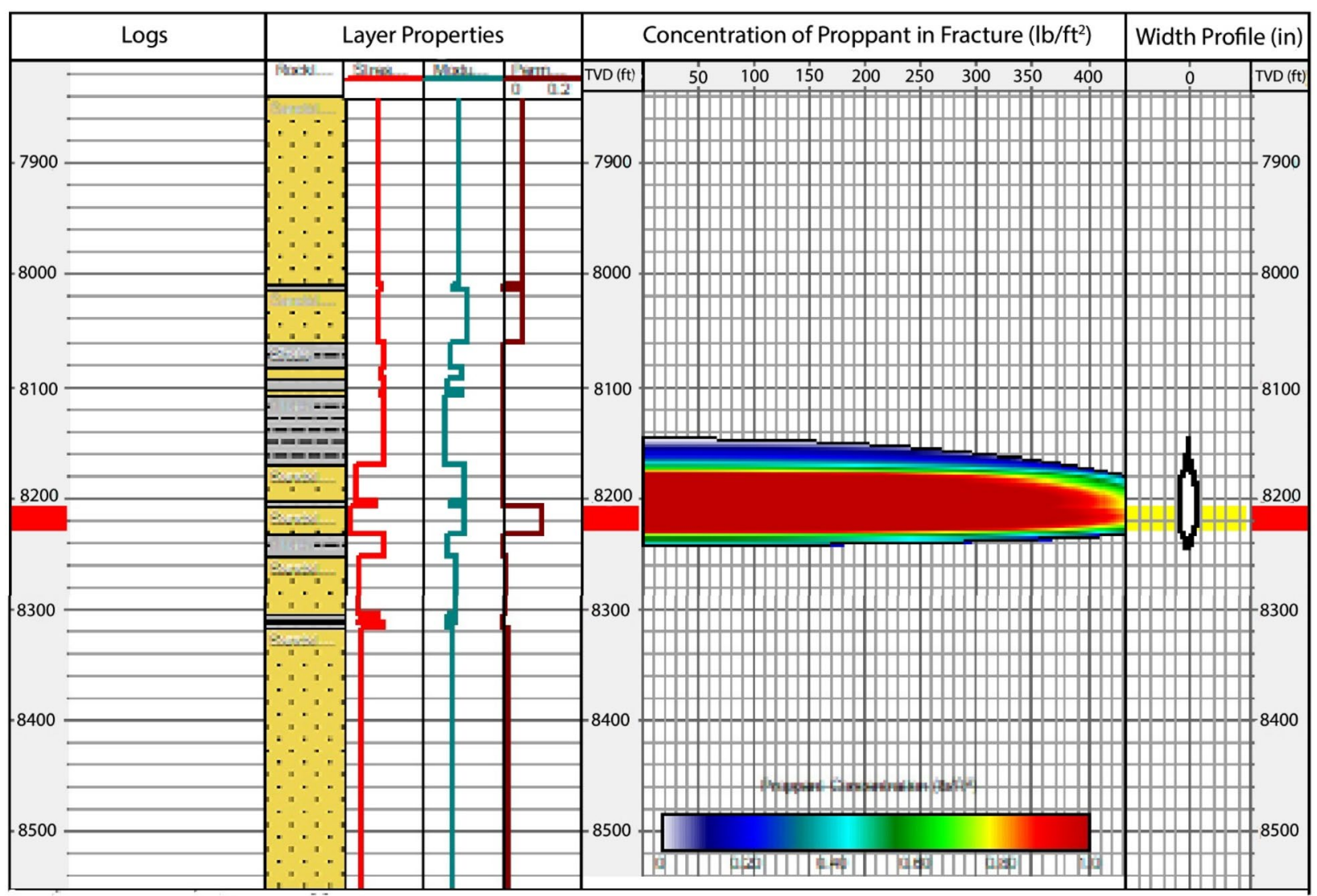

Fig. 19 Profile of propped fracture height growth into adjacent layers

gravity case attained a higher effective length than the 3.5 case. This is the ideal expected behavior. In both cases, the $13 \mathrm{bpm}$ rate produced a higher effective propped length than the other rates.

\section{Conclusions}

In this study, we utilized 2D, Pseudo-3D and 3D simulation models to optimize hydraulic fracturing design, and investigate how fracturing treatment parameters influence the hydraulic fracturing processes. We utilized field data from 2 unconventional horizontal wells in Eagle Ford formation, and grouped our analyses intro 5 case studies.

Our results show that fracture clusters with optimal lengths provide better and optimized hydraulic fracture treatment in some the cases investigated yielding greater proppant coverage, fracture conductivity, stimulated reservoir volume (SRV), fracture half-length, and propped length. Increase in fracture clusters will result in stress shadowing and interference, thereby impeding the growth of nucleated fractures and eventually led to a collapse of some the propagating fractures. This will yield lower SRVs and fluid recovery, which can result in ineffective hydraulic fracturing process in unconventional reservoirs. We therefore suggest in hydraulic fracturing design, not all fracture clusters should be activated due to stress shadowing and interference observed, to achieve optimum results. At high closure stress formations (>5000 psi), proppant configurations with higher strengths should be selected to achieve higher propped fracture geometry and SRVs. While the high-density proppants yielded the greater fracture lengths, the low-density proppants produced greater effective propped-fracture lengths. In our fluid injection rate sensitivity analyses on dimensionless 
Fig. 20 Effect of frac-fluid viscosity on fracture parameters: a dimensionless fracture conductivity; $\mathbf{b}$ propped fracture length

\section{Effect of Fracturing Fluid Viscosity on Fracture Parameters}
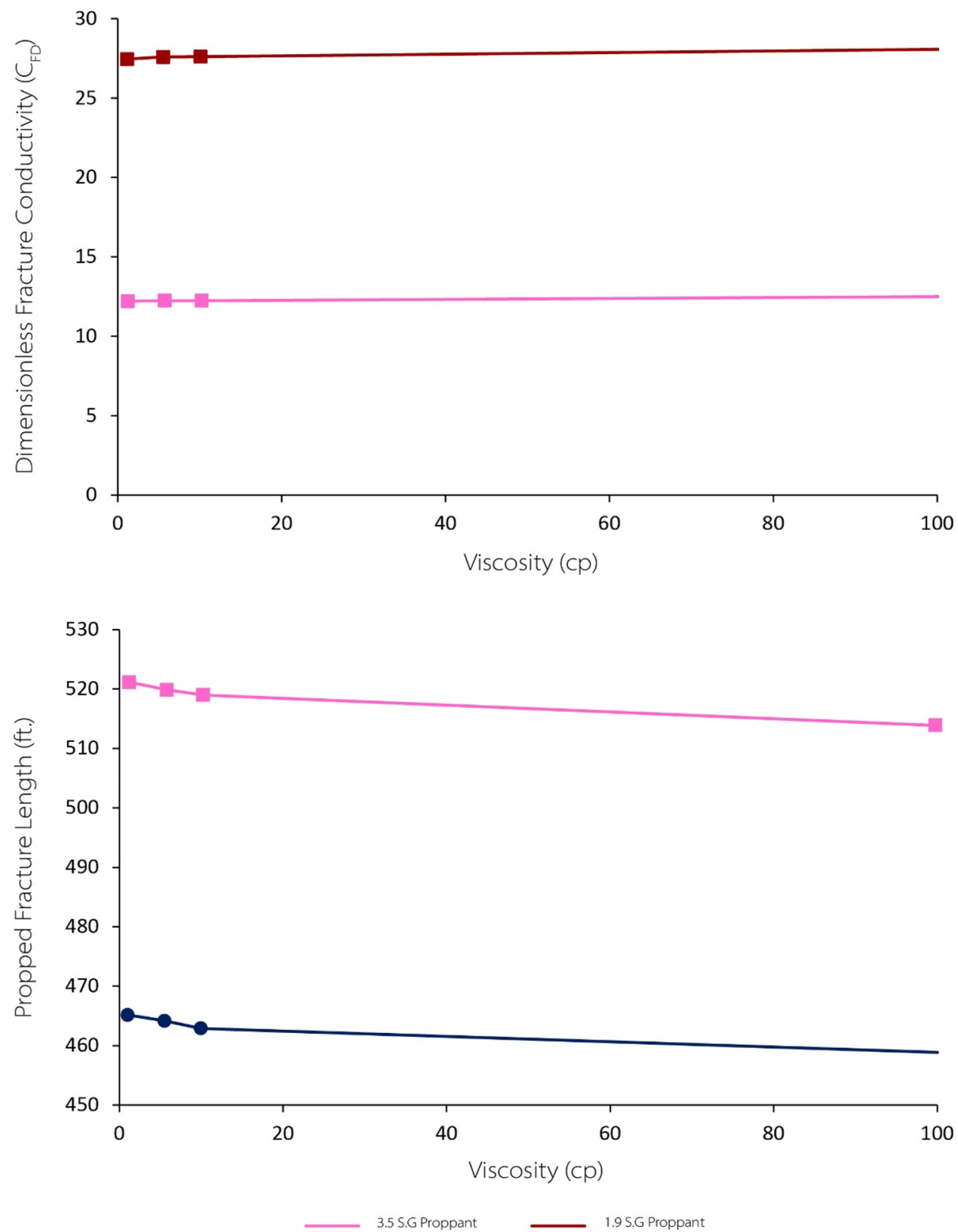

fracture conductivity $\left(\mathrm{C}_{\mathrm{FD}}\right)$, high-density proppants yield lower $C_{F D}$, while lower-density proppants yield higher $C_{F D}$. Furthermore, our results show that injection rate of $13 \mathrm{bpm}$ yielded the greatest fracture length, and effective propped length for high- and low-density proppants.

Our study provides an insight into optimizing hydraulic fracturing designs, and the critical impact of fracturing treatment parameters on hydraulic fracturing process and matrix-stimulation operations. This study is limited to Eagle Ford shale play, and therefore, data from other unconventional formations can be incorporated to further this study. Furthermore, this study can be further advanced by: (1) characterizing and analyzing the subsurface cores; (2) Further study on identifying the stress regime of the well; (3) developing a strong aquifersupport. This recommendations would further bolster hydraulic fracturing design and predictions to provide valuable critical decision-making during well completion, and stimulation operations. 
Fig. 21 Effect of pump injection rate on effective propped fracture length

\section{Effect of Pump Injection Rate on Effective Propped Length}

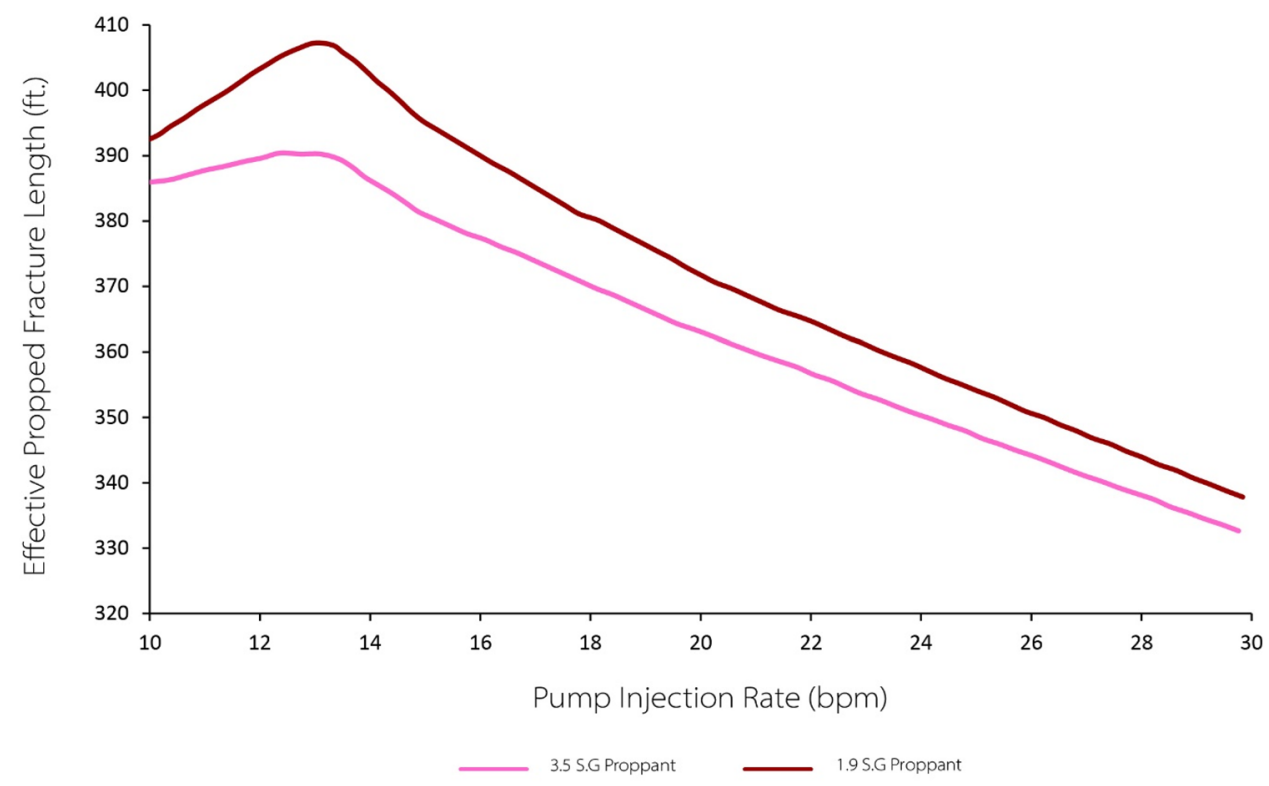

Acknowledgements The authors are grateful to NSI Technologies for the Stimplan ${ }^{\mathrm{TM}}$ software utilized for this study.

\section{Compliance with ethical standards}

Conflict of interest The authors declare that they have no conflict of interest.

\section{References}

1. EIA (2018) Short-term energy outlook. Energy information administration. US Department of Energy, Germantown

2. EIA (2019) EIA adds new play production data to shale gas and tight oil reports. Energy information administration, US Department of Energy. https://www.eia.gov/todayinenergy/detai I.php?id=38372

3. Germanovich LN, Hurt RS, Ayoub JA, Siebrits E, Norman D, Ispas I, Montgomery CT (2012) Experimental study of hydraulic fracturing in unconsolidated materials. Soc Pet Eng. https://doi. org/10.2118/151827-MS

4. Gil I, Nagel N, Sanchez-Nagel M, Damjanac B (2011) The effect of operational parameters on hydraulic fracture propagation in naturally fractured reservoirs-getting control of the fracture optimization process. American Rock Mechanics Association, ARMA, Alexandria

5. Maity D, Ciezobka J, Salehi I (2019) Fracture spacing design for multistage hydraulic fracturing completions for improved productivity. In: Aminzadeh F (ed) Hydraulic fracturing and well stimulation, 1st edn. Wiley, New York, pp 99-124

6. Wigwe ME, Bougre ES, Watson MC et al (2020) Comparative evaluation of multi-basin production performance and application of spatio-temporal models for unconventional oil and gas production prediction. J Pet Explor Prod Technol. https:// doi.org/10.1007/s13202-020-00960-y

7. Nwabuoku KC (2011) Increasing lateral coverage in Eagle Ford horizontal shale completion. Soc Pet Eng. https://doi. org/10.2118/147549-MS

8. Ingram SR, Lahman M, Persac S (2014) Methods improve stimulation efficiency of perforation clusters in completions. Soc Pet Eng. https://doi.org/10.2118/0414-0032-JPT

9. Yi SS, Wu C-H, Sharma MM (2018) Proppant distribution among multiple perforation clusters in plug-and-perforate stages. Soc Pet Eng. https://doi.org/10.2118/184861-PA

10. Kolawole O, Ispas I (2020) Interaction between hydraulic fractures and natural fractures: current status and prospective directions. J Pet Explor Prod Technol 10:1613-1634. https://doi. org/10.1007/s13202-019-00778-3

11. Cheng $Y$ (2012) Impacts of the number of perforation clusters and cluster spacing on production performance of horizontal shale-gas wells. Soc Pet Eng. https://doi.org/10.2118/138843-PA

12. Michael A, Habibi A, Rios R (2018) Three stress-shadowing mitigation techniques for hydraulic fracturing operations: an overview. The way ahead. https://pubs.spe.org/en/twa/twa-artic le-detail/?art=4671

13. Terracina JM, Turner JM, Collins DH, Spillars S (2010) Proppant selection and its effect on the results of fracturing treatments performed in shale formations. Soc Pet Eng. https://doi. org/10.2118/135502-MS

14. Harris PC, Morgan RG, Heath SJ (2005) Measurement of proppant transport of frac fluids. Soc Pet Eng. https://doi. org/10.2118/95287-MS

15. Harris PC, Walters HG, Bryant J (2008) Prediction of proppant transport from rheological data. Soc Pet Eng. https://doi. org/10.2118/115298-MS

16. Kolawole O, Esmaeilpour S, Hunky R, Saleh L, Ali-Alhaj HK, Marghani M (2019) Optimization of hydraulic fracturing design in unconventional formations: impact of treatment parameters. Soc Pet Eng. https://doi.org/10.2118/198031-MS 
17. Wigwe M, Kolawole O, Watson M, Ispas I, Li W (2019) Influence of fracture treatment parameters on hydraulic fracturing optimization in unconventional formations. American Rock Mechanics Association, ARMA-CUPB, Alexandria

18. Gong X, Tian Y, McVay DA, Ayers WB, Lee J (2013) Assessment of Eagle Ford shale oil and gas resources. Soc Pet Eng. https://doi. org/10.2118/167241-MS

19. Shelley RF, Saugier LD, Al-Tailji W, Guliyev N, Shah K (2012) Understanding hydraulic fracture stimulated horizontal Eagle Ford completions. Soc Pet Eng. https://doi.org/10.2118/15253 3-MS

20. Pope CD, Palisch T, Saldungaray P (2012) Improving completion and stimulation effectiveness in unconventional reservoirs- field results in the Eagle Ford Shale of North America. Soc Pet Eng. https://doi.org/10.2118/152839-MS

21. Khristianovich SA (1955) Formation of vertical fractures by means of highly viscous liquid. In: Proceeding: 4th World Petroleum Congress, Rome, Italy, June 6-15, WPC-6132

22. Geertsma J, de Klerk F (1969) A rapid method of predicting width and extent of hydraulically induced fractures. J Pet Tech 21:1571-1581. https://doi.org/10.2118/2458-PA

23. Perkins T, Kern $L$ (1961) Widths of hydraulic fractures. J Pet Tech. https://doi.org/10.2118/89-PA

24. Nordgren R (1972) Propagation of vertical hydraulic fracture. Soc Pet Eng. https://doi.org/10.2118/3009-PA

25. Daneshy AA (1978) Hydraulic fracture propagation in layered formations. Soc Pet Eng. https://doi.org/10.2118/6088-PA

26. Erickson AJ, Weiss PT, Gulliver JS (2013) Optimizing stormwater treatment practices: a handbook of assessment and maintenance, 1st edn. Springer, New York

27. Gadde PB, Liu Y, Norman J, Bonnecaze R, Sharma MM (2004) Modeling proppant settling in water-fracs. Soc Pet Eng. https:// doi.org/10.2118/89875-MS
28. Defeu C, Garcia GF, Ejofodomi E, Shan D, Alimahomed F (2018) Time dependent depletion of parent well and impact on well spacing in the wolfcamp delaware basin. Soc Pet Eng. https:// doi.org/10.2118/191799-MS

29. Ajisafe $F$, Reid $M$, Porter $H$, Fox D, Wigger E, Drouillard $M$ et al (2019) Understanding and mitigating depletion effects in infill wells for optimized production. Soc Pet Eng. https://doi. org/10.2118/197078-MS

30. Manchanda R, Bhardwaj P, Hwang J, Sharma MM (2018) Parent-child fracture interference: explanation and mitigation of child well underperformance. Soc Pet Eng. https://doi. org/10.2118/189849-MS

31. Guo X, Wu K, An C, Tang J, Killough J (2019) Numerical investigation of effects of subsequent parent-well injection on interwell fracturing interference using reservoir-geomechanics-fracturing modeling. Soc Pet Eng. https://doi.org/10.2118/195580-PA

32. Guo X, Wu K, Killough J, Tang J (2019) Understanding the mechanism of interwell fracturing interference with reservoir/geomechanics/fracturing modeling in Eagle Ford Shale. Soc Pet Eng. https://doi.org/10.2118/194493-PA

33. Michaels IH, Mostofi M, Richard T (2019) An experimental study of the wear of polycrystalline diamond compact bits. American Rock Mechanics Association ARMA, Alexandria

34. Wood WD, Brannon HD, Rickards AR, Stephenson C (2003) Ultralightweight proppant development yields exciting new opportunities in hydraulic fracturing design. Soc Pet Eng. https://doi. org/10.2118/84309-MS

Publisher's Note Springer Nature remains neutral with regard to jurisdictional claims in published maps and institutional affiliations. 